\title{
LA MONEDA EN LOS AMBIENTES INDUSTRIALES PESQUERO-CONSERVEROS DE LA COSTA GADITANA: SU USO RITUAL Y SU VALOR RELIGIOSO
}

\section{Ancient coin in the context of industrial fishery environments in the coastline around Cádiz: its ritual use and its religious value}

\author{
Alicia Arévalo González ${ }^{1}$ \\ Recibido el 1 de abril de 2009. Aceptado el 30 de agosto de 2009
}

\begin{abstract}
Resumen. El objetivo que pretendemos en estas páginas es exponer los testimonios del uso cultual de la moneda en la costa gaditana, a través del análisis de los hallazgos monetales procedentes de ambientes industriales. Se analizan dos cetariae y una figlina en las que nos consta que se han recogido ofrendas monetales. Se presentan todas las monedas clasificadas y se hace un estudio de su uso cultual, que aporta datos significativos sobre las creencias religiosas de los habitantes de esta costa.

Palabras claves: Costa gaditana, ambientes industriales, hallazgos monetales, monedas votivas.
\end{abstract}

\begin{abstract}
The aim of this paper is to present the evidence of the cultural use of coinage on the coastline around Cádiz, thought the analysis of the coinage found from industrial environments. This paper deals the finding of three cases of monetary offerings in figlinae and cetariae. On the other hand, their presence insight into the religions beliefs of the ancient inhabitants of this coastline.
\end{abstract}

Key words: Coastline around Cádiz, industrial environments, coins finds, votive coins.

\section{INTRODUCCION}

La función inicial con la que fue concebida una acuñación y los usos que se le dieron posteriormente son, a veces, muy distintos. En efecto, por un lado tenemos el propósito con el que el Estado acuñaba una emisión monetaria y por otro lado, el uso que las gentes daban cotidianamente a las monedas, que no tiene porque coincidir con la finalidad para las que fueron fabricadas.

La moneda, debido a su valor económico y porque en su nacimiento sirvió para representar iconográficamente a las divinidades veneradas en las ciudades, ofrecía una garantía y se envolvió de un carácter casi religioso, al mismo tiempo que daba prestigio a la propia ciudad que representaba. De igual modo, la moneda es testimonio de un culto oficial ciu- dadano, y por eso normalmente siempre se efigia en las acuñaciones la misma divinidad, el patrón o los patronos de la ciudad, como sabemos para aquellas ciudades cuya historia conocemos bien; así Gadir efigió siempre a su divinidad fenicia Melqart, aunque por sus contactos con la cultura helenistica había adoptado una iconografía más clásica, de ahí que lo encontremos representado como Heracles.

No debe extrañarnos que la moneda, por las connotaciones expuestas, se convirtiese en el objeto práctico más sencillo y rápido para ser susceptible de convertirse casi espontáneamente en ofrenda, exvoto o stipendium. Ya que constituia un pago o intercambio, a modo de recuerdo, para gozar de los favores deseados o solicitados a ciertas divinidades.

Es sabido que el registro de hallazgos monetarios en contextos religiosos es tan antiguo como la propia moneda, reflejo

(') Área de Arqueología, Facultad de Filosofía y Letras de la Universidad de Cádiz. Avda. Doctor Gómez Ulla, s/n. 11003 Cádiz. alicia.arevalo@uca.es 
de unas prácticas que, del mundo griego, pasaron al feniciopúnico en primer término, y a Roma, desde las Guerras Púnicas, como desarrollo final. Estos hallazgos pueden responder a factores de muy diversa índole, como depósitos fundacionales, mediante la colocación de objetos de cierto valor en los cimientos de especial relevancia, es decir, como una forma de sacralizar el lugar. Como exvotos, cuya finalidad será la del agradecimiento de algún favor o la de solicitar alguna gracia de la divinidad, esta práctica tal vez se deba a la idea de establecer con la divinidad la misma relación que se crea con el comercio; es decir, si para obtener un objeto debe pagarse, para lograr un favor se adopta idéntico criterio. Pero además al ser las monedas portadoras de una iconografía en muchos casos sacra, pudo ser utilizada por su valor religioso, pasando a incorporarse dentro de las ofrendas votivas. Por último, debemos mencionar los thesauri, moneda destinada a fines litúrgicos tales como el pago de los sacrificios. Por tanto, el uso de la moneda en los lugares de culto pudo ser doble, con valor monetario para el pago de servicios, de objetos cultuales y de sacrificios, y como ofrenda perse. Ahora bien, tampoco se debe olvidar que no todos los hallazgos monetarios efectuados en lugares de culto debieron tener un significado religioso, sino que también han podido ser resultado de pérdidas casuales en el lugar. De ahí que sólo se pueda llegar a determinar el sentido preciso de este tipo de hallazgos a partir de excavaciones y estudios detallados, ya que es la única fuente de información con la que se cuenta, al carecer de referencias textuales.

Tenemos constancia, por estudios arqueológicos, que desde el siglo III a. C. se ha dado en la Península Ibérica la presencia de monedas en espacios sacros (Alfaro 1993: 261276; Campo 1993: 193-205; Campo 2006: 52-54; Arévalo y Marcos 2000: 28-37; Arévalo 2006 b: 84-88), en manantiales termales (Abad 1992: 133-192; Abad 2006: 131-149), o en necrópolis formando parte de actos rituales (Alfaro 1993: 261-276; Campo 1993: 193-205; Campo 2006: 54-66; Arévalo 2006 b: 77-84, Arévalo, e.p. a y b). Sin embargo, nosotros queremos llamar la atención sobre un aspecto menos conocido y estudiado como es la participación de la moneda en actos rituales realizados en ambientes industriales. En este contexto centraremos nuestra aportación, la cual aspira a compilar las evidencias actualmente disponibles en la costa gaditana sobre la presencia de monedas depositadas con un extremado cuidado y de una forma claramente intencionada en establecimientos pesqueros y conserveros, así como en los alfares destinados a fabricar gran parte de los contenedores de estos productos piscícolas, sin duda para asegurar la continuidad de la actividad y la prosperidad de la misma mediante la realización de ofrendas, al ser esta actividad la base de la economía gaditana.
Si bien previamente, realizaremos algunas observaciones generales sobre la necesidad de estudiar las monedas de las cetariae y figlinae de esta región. Ya que a pesar del gran avance realizado en la investigación sobre estos ambientes industriales son aún muchas las cuestiones que quedan por analizar, como se ha expuesto recientemente en los dos congresos recientemente celebrados en Cádiz sobre este tipo de industrias (Lagóstena y Bernal 2004: 39-123; Lagóstena, Bernal y Arévalo 2007), y no cabe duda que uno de ellos es el estudio del tipo de numerario que circulaba en estos ambientes.

\section{LA MONEDA EN LAS CETARIAE Y FIGLINAE GADITANAS: UNA RECIENTE LIINEA DE INVESTIGACIÓN}

La costa gaditana ha constituido, desde los inicios de la investigación arqueológica, un espacio privilegiado para el conocimiento de la producción conservera vinculada con los productos del mar (Ponsich 1988; Curtis 1991; Lagóstena 2001; Etienne y Mayet 2002). Al amparo de esta explotación y en relación con la comercialización de estos productos surgieron en esta zona figlinae costeras, de ahí también que las manufacturas cerámicas predominantes sean las vinculadas con la producción anfórica, subsidiarias de esta importante industria (Lagóstena 1996; García 1998). La mayor atención prestada en los últimos años a este tipo de industrias en la costa gaditana, gracias a las numerosas intervenciones efectuadas en dicho ámbito geográfico, ha permitido ir conociendo mejor esta parcela de su historia económica en la Antigüedad.

Aunque son muchas las líneas de trabajo para el futuro sobre esta parcela de la Arqueología de la Producción en el ámbito gaditano, como se ha puesto de manifiesto en diferentes foros (Bernal y Lagóstena 2004; Lagóstena, Bernal y Arévalo 2007), está aún pendiente un estudio exhaustivo sobre el tipo de numerario que circulaba, y para ello es necesario, previamente, ir dando a conocer las monedas que aparecen en los alfares y en las fábricas de salazón excavadas, material al que normalmente se ha prestado muy poca atención, según se deduce de las referencias genéricas a monedas que encontramos en las respectivas publicaciones. Aspecto éste mejor documentado en otros ámbitos industriales de la Península lbérica, como el minero o el agrícola (Arévalo 1994: 39-48; Arévalo 1996: 51-82; Arévalo 1999; Arévalo 2000: 37-55; Chaves 1987-88: 613-617; Chaves y Otero 2002: 163-230; García-Bellido 1982; García-Bellido 1986: 13-46, García-Bellido 1999: 55-70).

Esta carencia es lo que nos ha llevado a abrir una línea de investigación² dirigida a recoger, analizar y estudiar de

(2) Esta investigación se enmarca dentro de las actuaciones del Grupo de Investigación "El Círculo del Estrecho de Gibraltar en la Historia. Estudio diacrónico y geoarqueológico desde la Prehistoria a la Antigüedad Tardia" (HUM-440 del IV PAI). Por otra parte, se integra dentro del Proyecto de Investigación denominado "Estudio y catalogación de las monedas antiguas del Museo de Cádiz", subvencionado por la Consejería de Cultura de la Junta de Andalucía, cuyos primeros resultados han sido ya presentados (Arévalo 2006 a: 297-308). 
forma sistemática la presencia de numerario en este tipo de enclaves industriales (Arévalo 2004: 515-522; Arévalo 2005: 471-479). Aunque no es éste el objetivo del trabajo que ahora presentamos, pues trasciende al análisis que pretendemos acometer aquí, sí queremos dar algunas pinceladas, y hacer una llamada de atención sobre la necesidad de contar con un Proyecto de Investigación específico para poder profundizar en estas cuestiones, dado el papel preponderante de la industria de los salsamenta y salsas de pescado por la que fue conocida esta zona en el Mundo Antiguo.

La amplitud de la costa gaditana y el propio devenir historiográfico de las investigaciones han generado, a efectos de nuestro trabajo, tres epicentros para el conocimiento de estas industrias. En primer lugar la Bahía de Cádiz y su zona de influencia; como segundo punto neurálgico, la Bahía de de Algeciras; por último, el tramo costero litoral entre las zonas anteriormente mencionadas, zona en la cual la intensidad de los estudios ha sido mucho menor, a excepción de las conocidas cetariae de Baelo Claudia. Serán precisamente en estas tres zonas sobre las que centraremos nuestro discurso.

\subsection{Los centros industriales de la bahía de Cádiz y su zona de influencia: el primer estudio numismático sistemático.}

Gadir y la posterior Gades es una ciudad que contaba con una larga vinculación con la industria pesquero-conservera, como se evidencia a través de las fuentes literarias y de la documentación arqueológica (Expósito 2007a: 367385; Expósito 2007b). También sus monedas muestran, mejor que ninguna otra ceca del mediodía peninsular, una rica y variada tipología de iconos marinos, convirtiendo estas imágenes en emblemas ciudadanos, al tiempo que se alude mejor que en ninguna otra ciudad costera a la actividad base de su economía (Alfaro 1988; Arévalo 2002-2003: 242-246).

A pesar de la clara vinculación mostrada por sus acuñaciones, no contábamos, hasta hace muy poco tiempo, con un estudio que analizara la presencia de numerario en este tipo de ambientes industriales. Recientemente se ha realizado un Trabajo de Investigación de Tercer Ciclo dirigido a recoger y analizar las monedas procedentes de las cetariae y figlinae de la bahía de Cádiz (Sánchez Loaiza 2008; Sánchez Loaiza e.p).

En este trabajo se presentan un total de 120 monedas procedentes de 22 yacimientos identificados como cetariae y figlinae, remitimos al lector a este trabajo tanto para conocer el análisis exhaustivo de los registros monetarios de cada yacimiento, como para el estudio numismático pormenorizado que se acomete sobre el aprovisionamiento, circulación y uso de la moneda en este tipo de centros industriales. Ahora, tan sólo destacaremos algunos de los aspectos más significativos que permitan conocer la aportación de este detallado estudio.
En la bahía de Cádiz se han registrado hallazgos monetales en quince cetariae: doce situadas en la actual ciudad de Cádiz, una en el municipio de San Fernando, otra en el Puerto de Santa Maria, y por último, la localizada en Sanlúcar de Barrameda. En cuanto a los hallazgos monetarios en figlinae se han recogido en siete yacimientos: dos en Cádiz, uno en el Puerto de Santa María, dos en San Fernando y dos en Puerto Real.

Destacar que más de la mitad de las monedas encontradas corresponden a ejemplares de la ceca gaditana con cincuenta y cinco piezas, estando representadas todas sus series, salvo la segunda que al ser de plata podría explicar su ausencia. Ya que al igual que el resto del numerario encontrado, son las monedas de escaso valor, y por lo tanto de bronce, las que parece que circularon con más frecuencia en este tipo de ambientes industriales. Del resto de los talleres hispánicos sólo proceden seis ejemplares -tres de Carteia y un ejemplar-, respectivamente, de las cecas de Castulo, Lascuta y Malaka. De moneda foránea se han localizado siete monedas -seis de Massalia y una de Numidia-. El resto de los numismas son altoimperiales -un total de treinta y seis, donde destacan las veinticuatro monedas de Claudio, el resto está representado por dos ejemplares de cada uno de siguientes emperadores Tiberio, Calígula, Nerón, Vespasiano, y Domiciano, por último, un ejemplar de Trajano y otro de Adriano-, además de una pieza bajoimperial de Constantino I.

Del análisis de estos datos cabe resaltar algunos puntos: en primer lugar, la preeminencia del numerario local, lo que sin duda evidencia la estrecha relación de la moneda de Gadir/Gades con este tipo de industrias. En segundo lugar, la escasa presencia de numerario hispánico y la ausencia de moneda romano-republicana. En tercer lugar, coincidiendo con uno de los períodos de mayor esplendor comercial y económico de esta zona se atestigua la presencia de numerario del siglo I d. C.; mientras que para el siglo II d. C. el único ejemplar recuperado, coincide con la falta de información sobre este tipo de ambientes industriales para este periodo cronológico. Por último, encontramos un acentuado vacío de información numismática a partir del siglo III, que parece ser más resultado de un mal conocimiento del funcionamiento industrial de esta etapa.

Además de la interesante y rica aportación de este trabajo, queremos resaltar lo ya apuntado por nosotros (Arévalo 2004: 522; Arévalo 2006 c: 69-100) sobre la conveniencia de analizar al unísono algunas de las contramarcas en monedas de Gadir (Alfaro 1988: 72) con los sellos alfareros sobre ánforas de producción gaditana (fig.1 y 2). En este sentido, hemos analizado la contramarca denominada como estrella y la estampilla en forma de roseta (Frutos Reyes y Muñoz Vicente 1994: 393-414), que aparece en ánforas elaboradas en el complejo alfarero de Torre Alta (San Fernando, Cádiz). Ambas presentan un diseño similar, pero además está constatada la existencia de una estampilla en un 


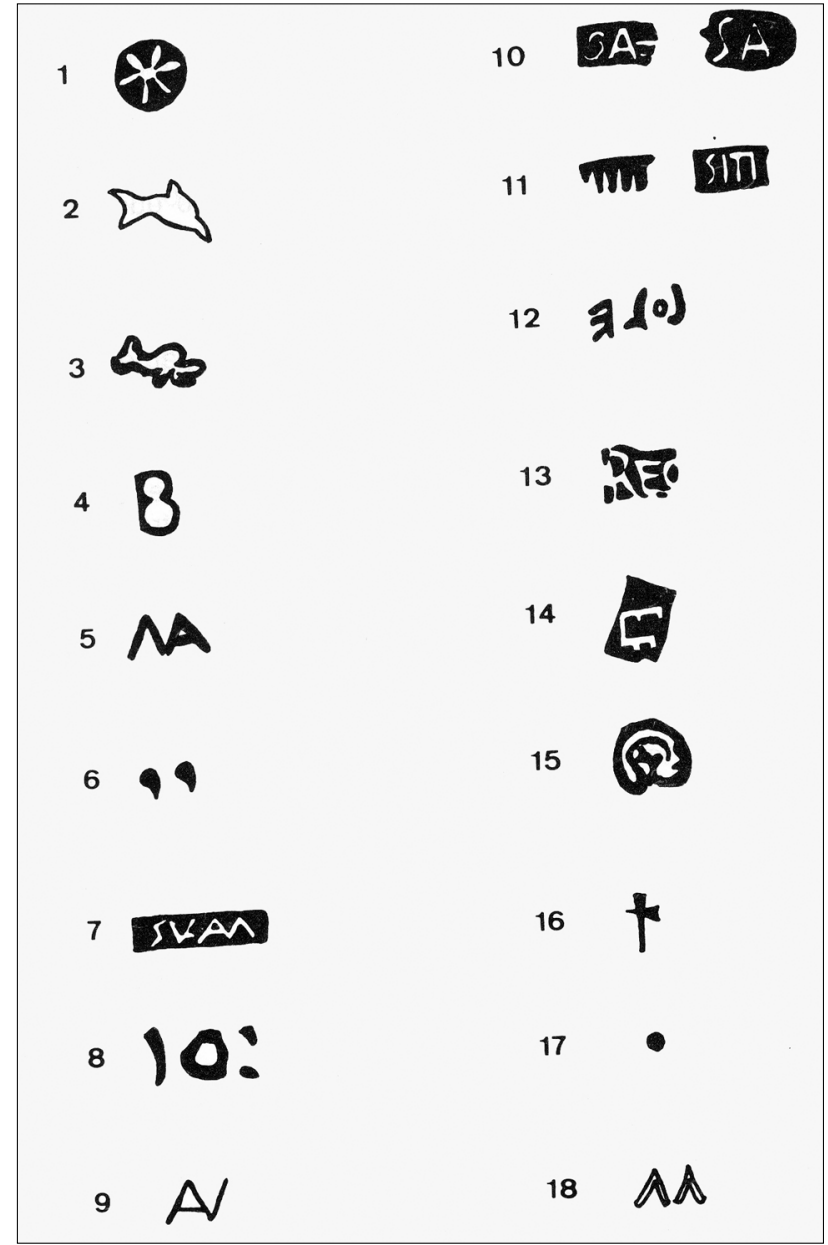

A FIgURA 1. Tipología de las contramarcas sobre monedas de Gadir/Gades (según Alfaro, 1988: 72).

ánfora de producción local, recuperada durante las excavaciones de la Plaza de Asdrúbal de Cádiz (Muñoz, Frutos y Berriatúa 1988: 502, fig. 8.1), donde figura una pareja de atunes similar a la que aparece en los reversos de las monedas Gadir (fig. 3), por lo que se podría relacionar ambos hechos y, más aún, vincular al menos algunas de las contramarcas monetales con la industria de salazones (Arévalo 2004: 522; Arévalo 2006 c: 69-100). Ya Alfaro (2000: 428-429) consideró que el hecho de que se encuentre la contramarca de la estrella exclusivamente sobre monedas de la serie IV de $\mathrm{Ga}$ dir, una emisión que se caracteriza por su mala factura, tal vez se deba a que fue rechazada por parte de los usuarios, lo que obligó a contramarcarla con un motivo que era conocido por todos al estar en relación con las salazones. Por desgracia, desconocemos el lugar de procedencia de las doce monedas contramarcas con estrella publicadas, pero es interesante resaltar que otra de las contramarcas más frecuentes en el numerario de Gadir, las del tipo delfín (fig. 4), aparece frecuentemente en Cádiz, en cetariae y en contextos alfareros relacionados con la producción de ánforas salsarias. En efecto, gracias al estudio de los lugares de procedencia de estas piezas, se ha comprobado que casi de forma exclusiva aparecen en el entorno de la bahía de Cádiz, y en lugares vinculados de una u otra forma con la industria de las salsamenta y salsas de pescado, por lo que hemos propuesto que estas contramarcas fueron aplicadas dentro de este ámbito económico, y con el objetivo de marcar una propiedad, para que no salieran de este ambiente industrial al que estaban adscritas. Por lo que las hemos denominado contramarcas "pesqueras" (Arévalo 2006c: 69-100), sumándose a las ya conocidas contramarcas mineras y militares.

Acabamos de mostrar de forma sucinta la rica información numismática e histórica que se puede extraer cuando se acometen este tipo de estudios. A continuación, expondremos un claro ejemplo procedente de la bahía de Cádiz donde además de mostrar la vinculación de la moneda con estos de ambientes industriales, se pone de manifiesto uno de los usos que las gentes que trabajaban en este tipo de industrias daban a las monedas, y que las vinculan con su faceta ritual y religiosa que tuvieron en la Antigüedad, como exponíamos en la introducción de este trabajo.

\subsubsection{El abandono ritual de un horno cerámico en el alfar de Torre Alta \\ (San Fernando, Cádiz)}

Recientemente se ha dado a conocer el hallazgo de dos monedas de bronce de la primera serie de Gadir (Arévalo 2004: 516-519) formando parte, junto a otros objetos, de un acto de abandono ritualizado en el horno 4 del complejo alfarero de Torre Alta (San Fernando, Cádiz). Este alfar, con una compleja secuencia de actuaciones arqueológicas y urbanísticas a través de los últimos quince años, ha proporcionado cinco estructuras fornáceas y una serie de escombreras, habiéndose podido establecer una secuencia de utilización de las instalaciones en cinco fases principales correspondientes al siglo III a.C. y la primera mitad del siglo II a.C., si bien la existencia de materiales de los siglos $\mathrm{V}$ y IV a.C. encontrados en superficie pueden quizás indicar una actividad anterior en las cercanías aún no documentada con amplitud (Sáez 2004: 707-710; Sáez 2008).

Fue precisamente el horno 4 (fig. 5), donde se ha documentado el acto ritual, el primero que se puso en funcionamiento en el taller alfarero, a tenor de la propia morfología arcaizante de la estructura y de que su entrada fue amortizada por el inicio de uso del vertedero del horno 3, habiéndole asignado una cronología de inicio de actividad de hacia mediados del siglo III a. C., mientras que su abandono se sitúa en los primeros años de la presencia bárcida en suelo peninsular. Aunque la continuidad del taller alfarero estaba ya asegurada pues poco antes de la amortización definitiva de este horno se lleva a cabo la construcción de una nueva estructura fornácea -el denominado horno 3-.

Nos interesa ahora destacar que el proceso de colmatación de este horno 4 debió ser complejo, formando parte de 


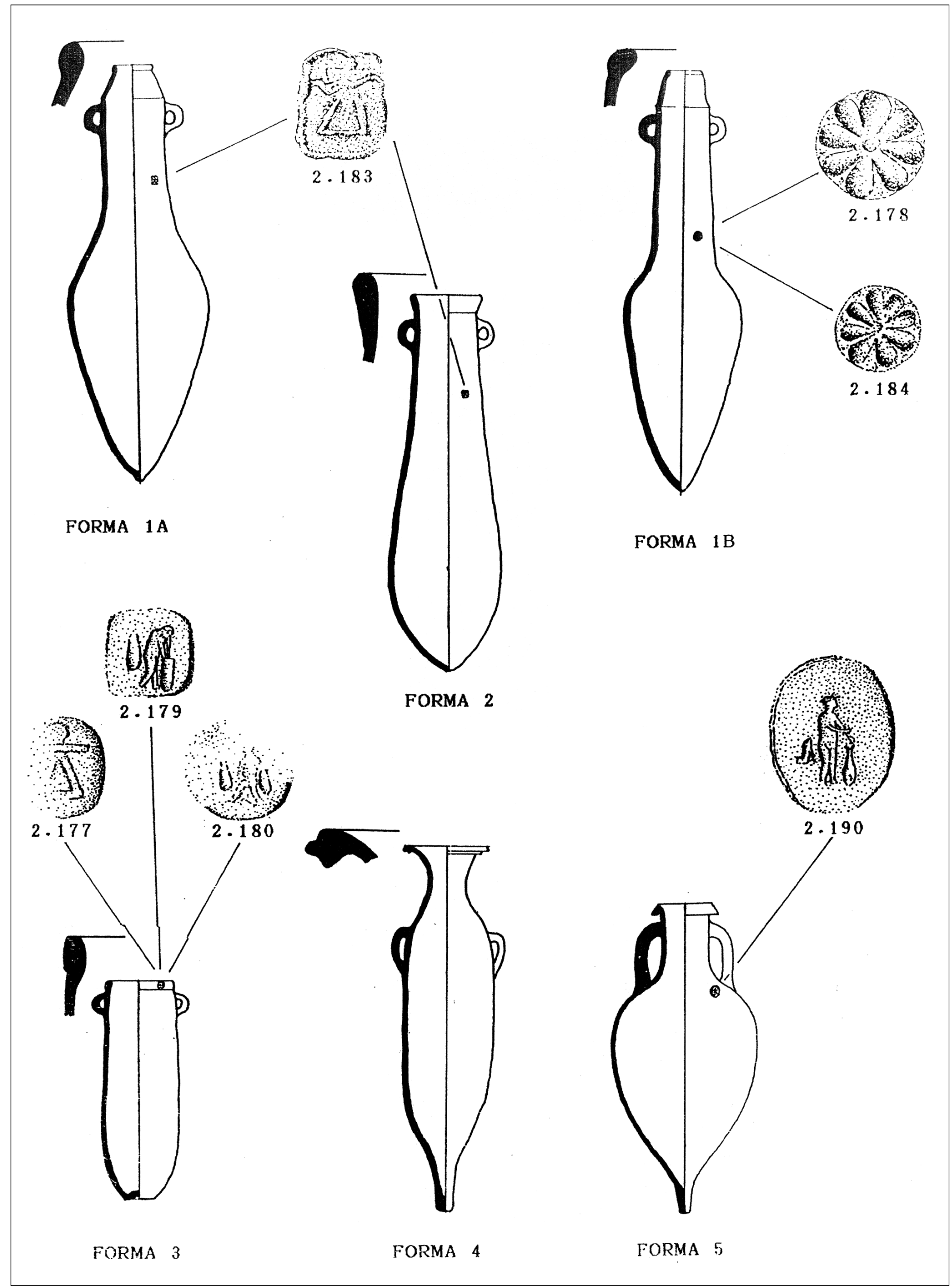

\ FiguRa 2. Estampillas sobre ánforas del complejo alfarero de Torre Alta, San Fernando (según Frutos y Muñoz, 1996). 


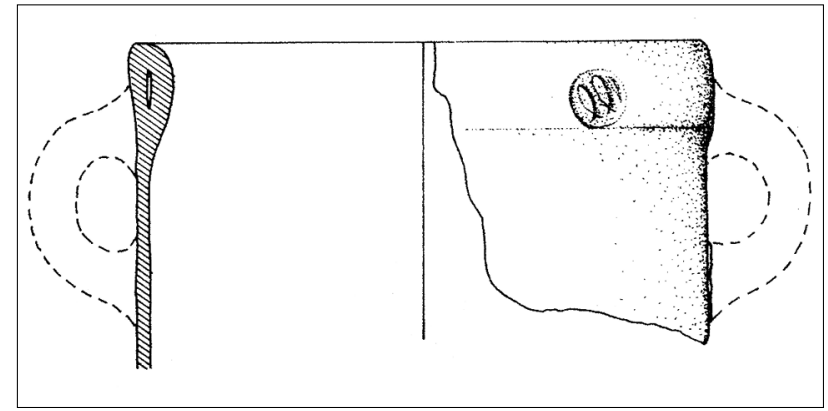

A Figura 3. Estampilla sobre ánfora hallada en la Plaza de Asdrúbal, Cádiz (según Muñoz, Frutos y Berriatúa, 1988).

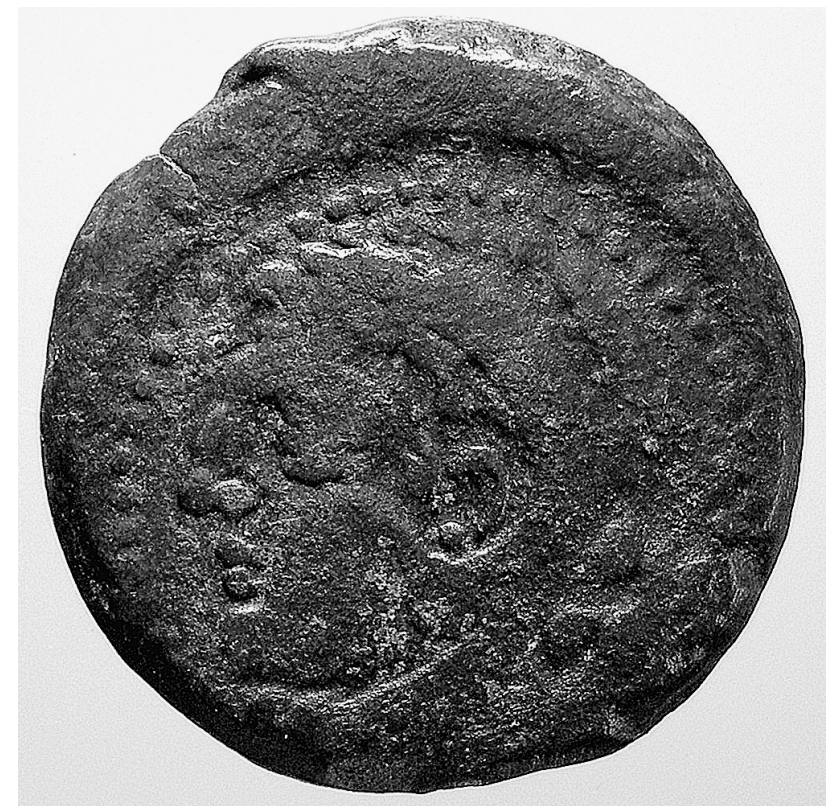

un ritual destinado a formalizar el abandono de la actividad de la estructura fornácea más antigua del alfar y también probablemente para intentar asegurar con ello la prosperidad de la industria todavía en funcionamiento. La información estratigráfica y el estudio microespacial de los objetos encontrados (Sáez 2004: 704-705; Sáez 2008: 213-243) apuntan a un elaborado ritual durante el proceso de amortización definitiva de la vetusta estructura, que ya no podía ser utilizada para la cocción de piezas cerámicas posiblemente por razones tecnológicas.

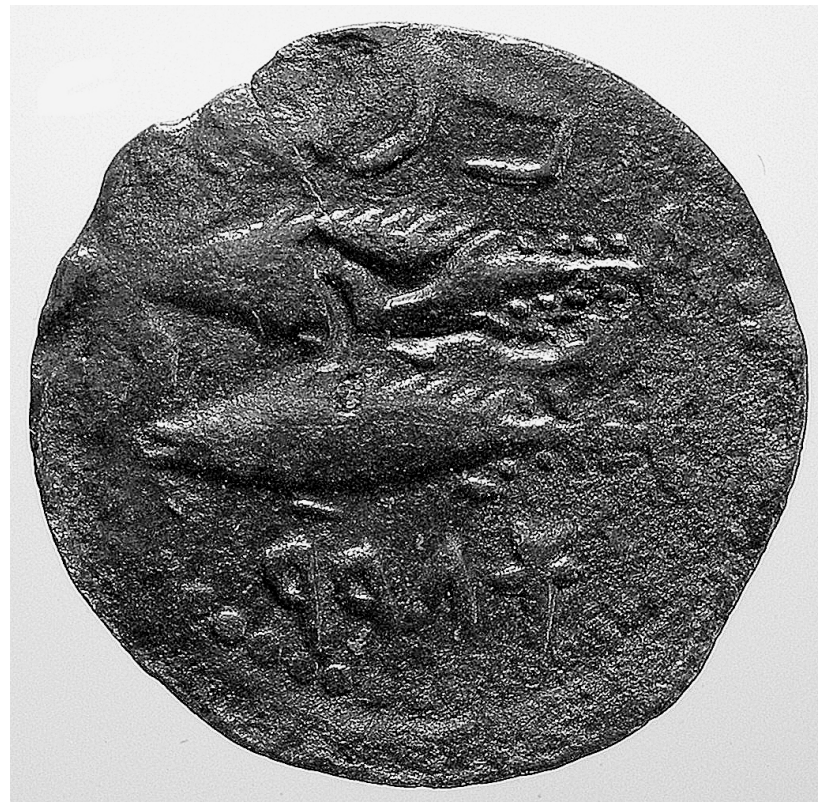

$\Delta$ Figura 4 a y b. Moneda de Gades contramarcada con delfín (Museo de Cádiz 22796).

A Figura 5. Horno 4 de Torre Alta (San Fernando, Cádiz) (cortesía de A. Sáez).

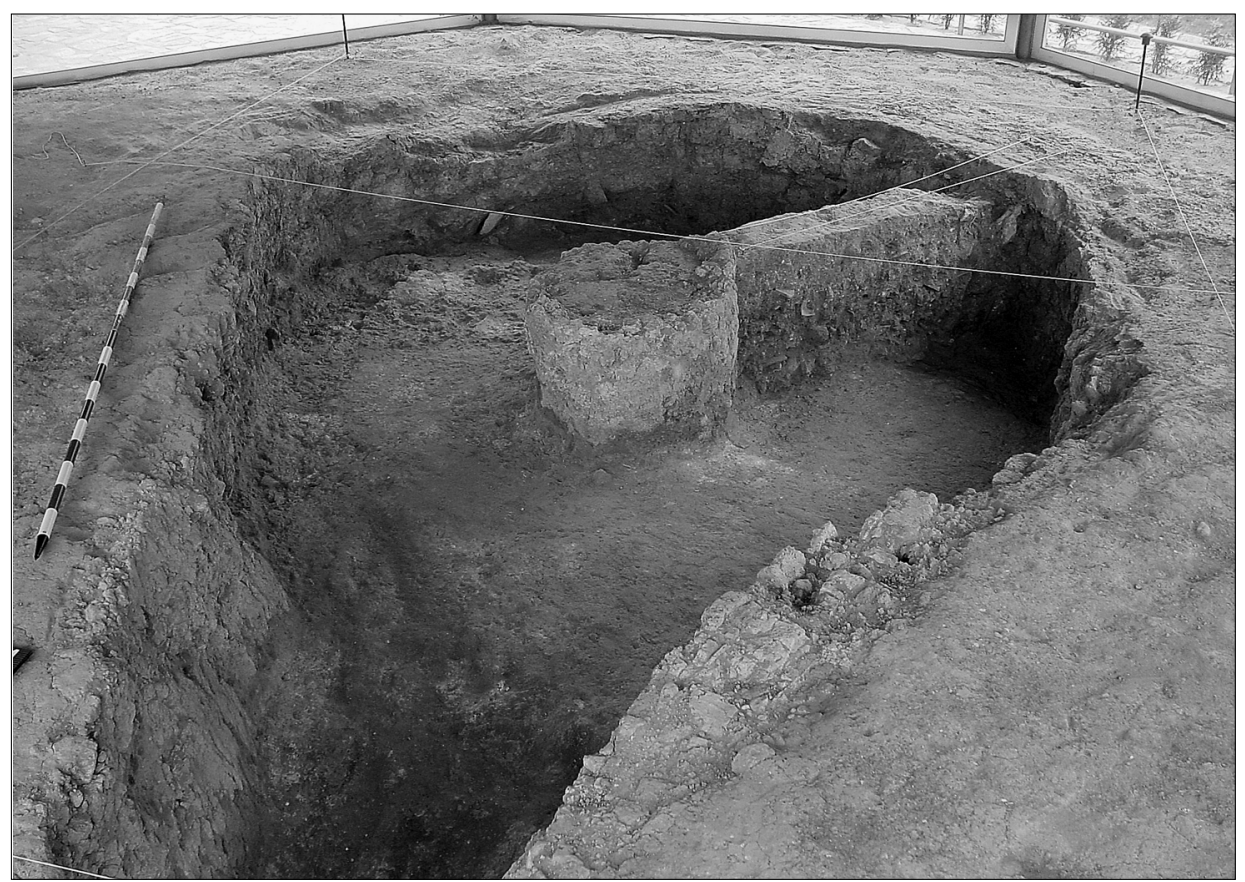


Desmontadas las partes útiles del horno y limpiadas de forma cuidadosa las ingentes cantidades de cenizas que debían haberse acumulado en la entrada y suelo de la cámara inferior, fruto de los últimos momentos de actividad, la estructura debió quedar totalmente vacía, a excepción de la columna central, y lista para su definitivo abandono. En estos momentos sobre varias zonas del suelo de la estructura se colocan una serie de objetos (fig. 6): una tinaja de borde subtriangular de tradición local, una grecoitalica de imitación de reducidas dimensiones y un cuello de ánfora local recortado que protegía a una jarrita de boca trilobulada en cuyo interior se encontraba un vaso de perfil en $\mathrm{S}$, todo ello colocado junto a la zona media de la pared Este del horno; otro vaso de perfil en $\mathrm{S}$ fue hallado junto a la columna central; una fusayola, un útil del alfarero - un alisador-, y una copa de barniz rojo fueron depositados en el ángulo sureste también junto a la pared; por último, las dos monedas de Gadir de la primera serie fueron colocados junto a la pared oeste, en un hueco dejado por los adobes que dieron consistencia térmica a la misma. Finalmente, los restos de la cámara de combustión y los objetos depositados en ella como ofrenda fueron sepultados por un relleno compuesto por un heterogéneo conjunto formado por las tierras arcillosas, propias del entorno inmediato al horno, y por los numerosos desechos de cerámicas y adobes que en ella se encontraban en este momento.

De los objetos que forman este depósito debemos señalar que entre los elementos cerámicos destacan los relacionados con la bebida: dos vasos, una jarrita y una copa barnizada, lo que podría estar indicando la realización de libaciones en el ritual; asimismo la tinaja pudo contener un producto líquido relacionado con los vasos y la jarra; la miniatura de ánfora grecoitálica se puede poner en relación con las numerosas miniaturas de ánforas documentadas en La Caleta (Cádiz), cuyo uso como ofrenda ha sido defendido (Muñoz 1993). Junto a ellos se encuentran elementos de uso personal y funcional como el alisador, sin duda con un valor sentimental alto para su poseedor, y la fusayola, objeto que es relativamente frecuente en varias cuevas-santuarios del levante peninsular (Martínez y Castellano 1995: 525-536), y que también se ha documentado entre los objetos que componían el ajuar de la tumba 36 de la zona $B$ de la necrópolis de Puente Noy (Almuñecar, Granada) (Molina, Ruiz y Huertas 1982: 82). Por último, las dos monedas en buen estado de conservación, pertenecientes a una misma emisión -Serie I de Alfaro (1988)- pero correspondientes a dos valores distintos - mitad y cuarto-, y con dos iconografías diferentes, en una figura Melqart a izquierda y en la otra, una cabeza frontal que para unos investigadores seria la representación de Helios, mientras que para otros seguiría siendo Melqart (figs. 7 y 8). Estas monedas que fueron emitidas a principios del siglo III a. C. no son coetáneas al momento de abandono, recordemos, primeros años de la presencia bárcida, pues para esos momentos ya se había emitido la serie de plata y de bronce con leyenda "acuñación u obra de Gadir" -series II y III-.

En efecto, no se escogen para este acto las nuevas monedas puestas ya en circulación sino la primera emisión, el determinar las razones que llevaron a tal selección es complicado; si bien hemos propuesto (Arévalo 2004: 517-518) que esta elección podría estar relacionada con la hipótesis defendida por algunos investigadores de que estas monedas fueran "obolos votivos" para el santuario de Melqart (García-Bellido y Blázquez 2001: 24 y 146), así como la posibilidad de que radicase en el templo dedicado a esta divinidad el inicio de estas acuñaciones y no a la comunidad cívica (Chaves y García Vargas 1991: 158-160; Alfaro 1993: 2728). En este sentido, se debe resaltar la vinculación de estas instalaciones de producción cerámica al ambiente sacro de las islas gaditanas, en especial al templo de Melqart ubicado en el extremo sur de este mismo término isleño, tanto a nivel ideológico como garante de la actividad comercial salazonera, así como posible poseedor de las propias zonas del archipiélago donde se asentaron los talleres (García 2001; García y Ferrer 2002). Quizás sea ésta la razón por la que se depositan estas monedas y no las coetáneas, ya que estas últimas al incluir la leyenda "acuñación de u obra de Gadir" están constatando que son acuñaciones de la ciudad y no del santuario, por lo que quizás se escogieron las primeras piezas como recuerdo de la función votiva que tuvieron en origen, pues poco después el numerario de Gadir se vincula con la actividad económica de la ciudad que, como ya hemos señalado, giraba en torno a la producción de conservas marinas y de los contenedores destinado a exportarlas, de ahí que sea frecuente su hallazgo en este tipo de ambientes industriales, como hemos mostrado en el apartado anterior.

\subsection{Las monedas de las cetariae de Baelo Claudia: algunas novedades}

Sobre las monedas procedentes de las factorías de salazones de Baelo Claudia poco podemos decir, pues aunque contamos con el estudio de las acuñaciones recuperadas en las distintas campañas de excavación efectuadas en la ciudad (Bost et al. 1987), donde se recogen 1906 ejemplares, por desgracia han sido publicados sin consignar el estrato en el que aparecen, y sin los materiales asociados, por lo que se hace necesario acometer un estudio en este sentido.

Sí que podemos aportar los nuevos hallazgos monetales procedentes de las intervenciones arqueológicas acometidas durante los Cursos Internacionales de Arqueología Clásica en Baelo Claudia, coorganizados por la Universidad de Cádiz y la Consejería de Cultura de la Junta de Andalucía, publicados en la memoria de las intervenciones arqueológicas realizadas en el barrio meridional entre el año 2000 y 2004 (Arévalo y Bernal 2007), que aunque no son muy numerosos, han apor- 


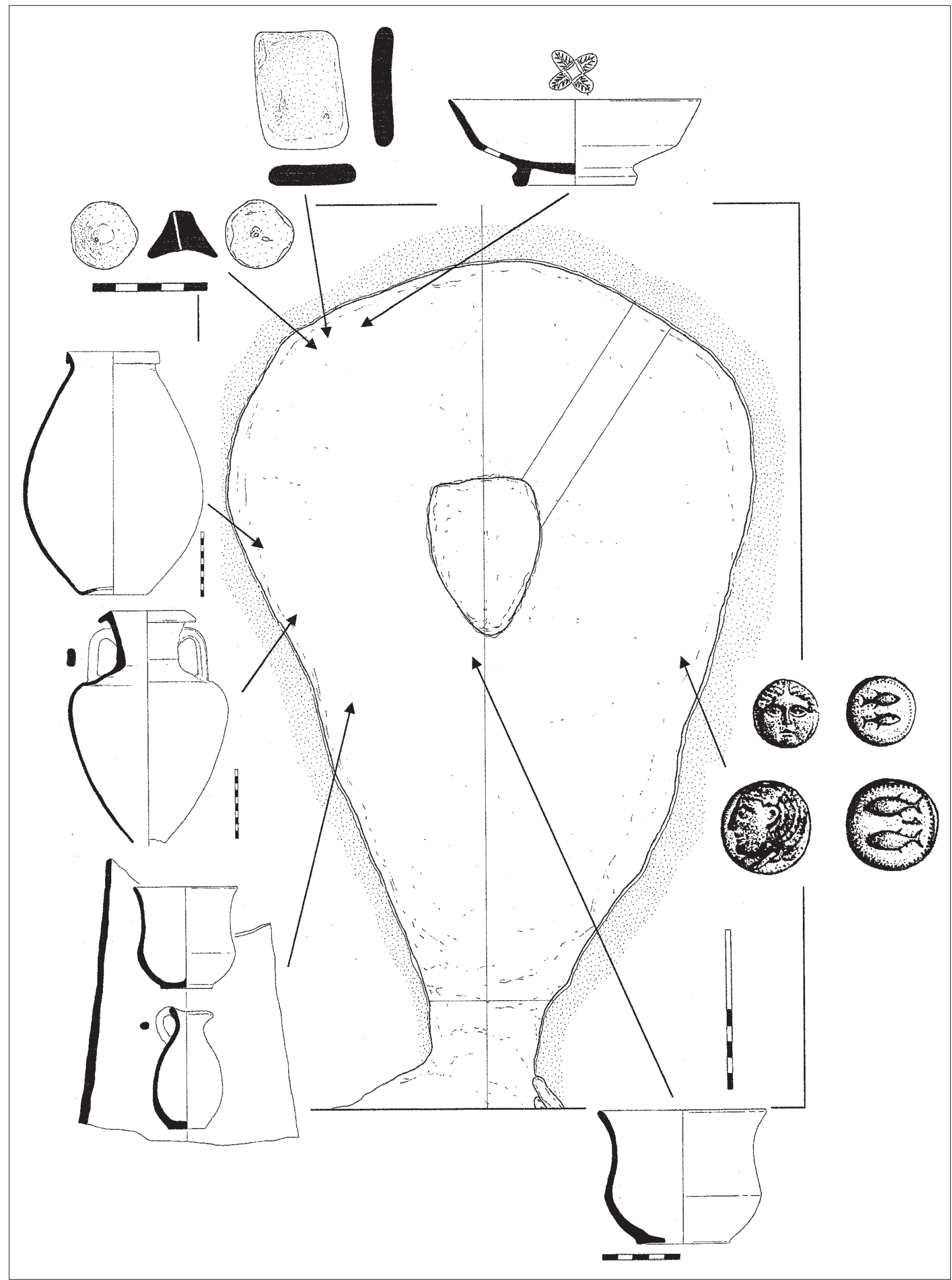

A FiguRA 6. Esquema gráfico de la distribución de los materiales documentados en el abandono del horno 4 de Torre Alta (San Fernando, Cádiz) (cortesía de A. Saéz). 

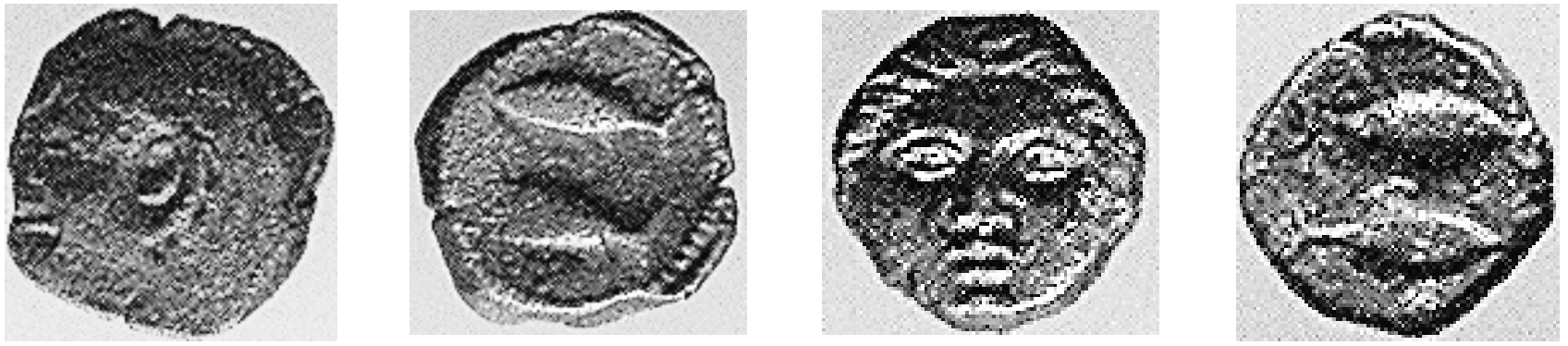

A Figuras 7 y 8. Divisores de bronce de Gadir procedentes del horno 4 de Torre Alta (Museo Municipal de San Fernando).

tado algunas datos de sumo interés (fig. 9). Las novedades más significativas de estas actuaciones arqueológicas derivan de la documentación de un horizonte republicano fechado a partir de mediados del siglo II a. C., constatado en todas las zonas en las cuales se ha intervenido en extensión, llegando hasta los niveles geológicos -sondeo 1, en el Conjunto Industrial VI (fig. 10), y sondeo 2, en el ahora denominado Edificio Meridional III-. Adicionalmente, en la intervención realizada en Punta Camarinal - El Anclón, en la playa de Bolonia, donde también han sido excavadas diversas habitaciones del mismo momento (Sondeos 4-6), únicos sondeos que no han proporcionado monedas. Por último, se ha intervenido arqueológicamente en el denominado Edificio Meridional VIII situado al oeste del cardo del barrio merdional (Sondeo 3), y en la zona al sur de la denominada Puerta de Carteia, y por lo tanto en la zona noreste del barrio meridional (Sondeos 7 y 8 ).

A continuación haremos una referencia sucinta a los nuevos hallazgos, remitiendo a la monografía antes citada para profundizar en ellos: dos semises de Carteia (en los Sondeos I y II), que por su especial importancia analizaremos a continuación; ocho antoninianos de Claudio II de ceca local documentados en las siguientes zonas: uno en la superficie del área interior del Edificio Meridional III (Bernal et al. 2007: 395-396), y siete en el Sondeo 3 del Edificio Meridional VIII en un estrato de colmatación datado en el último cuarto del siglo III d.C. (Bernal et al. 2007: 474-477); ocho bronces de Constantino I y familia encontrados en los sondeos 7 y 8 efectuados en la zona noreste del barrio meridonal en un contexto de la segunda mitad del siglo IV (Bernal et al. 2007: 458-460). En total un conjunto 18 monedas, de las que sólo abordaremos ahora las dos de Carteia, por ser importantes para entender antiguos hallazgos, especialmente uno de ellos efectuado durante la primera campaña de excavación de la Casa de Velásquez y que fue interpretado como depósito fundacional; el resto de los ejemplares al haber sido encontrados bien en superficie bien en niveles de colmatación, no son relevantes para el estudio que estamos realizando aquí.

Como acabamos de señalar, especialmente significativo ha sido el hallazgo de un semis de Carteia de la emisión 15 (CNH: 46, n 37; Chaves 1979: II, 15.A.a) en el sondeo 1 del

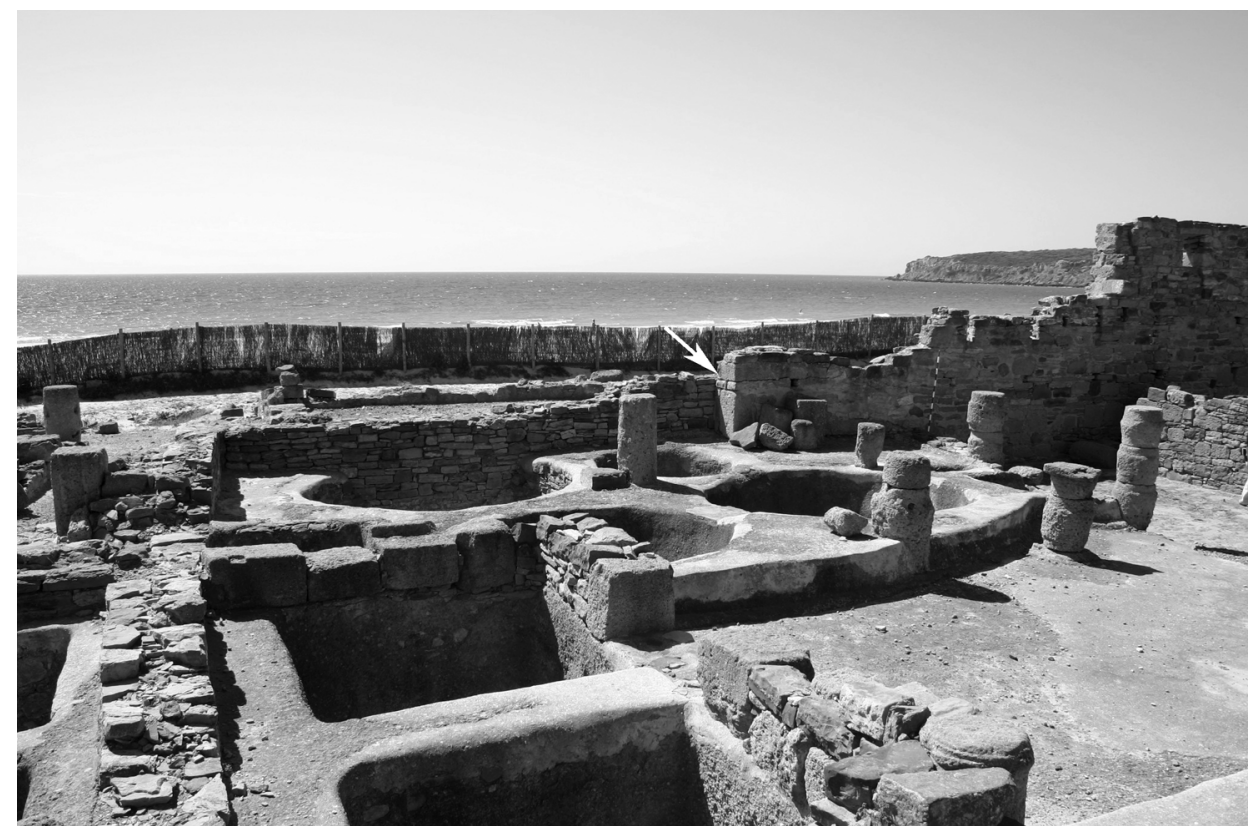

A Figura 9. Detalle de las cetariae de Baelo Claudia (Tarifa, Cádiz). 
A Figura 10. Últimos hallazgos de época romanarepublicana en la factoría de salazones de Baelo Claudia.

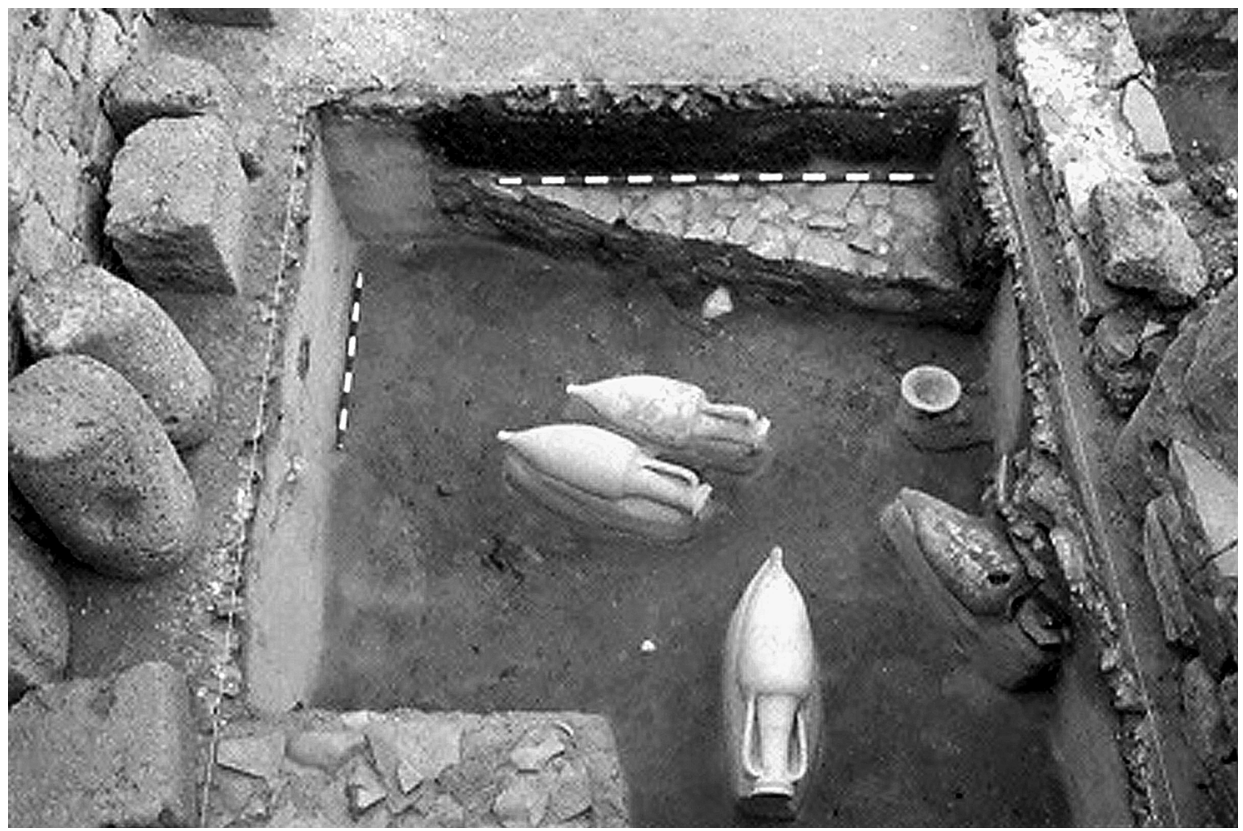

Conjunto Industrial VI o de las piletas troncocónicas (Bernal et al. 2007: 275-276) Su importancia se debe a que puede permitir perfilar mejor la cronología y la seriación de esta ceca, dado que se trata de un hallazgo encontrado en un claro contexto arqueológico fechado en el último tercio del siglo Il a. C (fig. 11). Constata además la presencia de este tipo de moneda en niveles republicanos, cuestión que hasta ahora no había sido suficientemente valorada, pues parecía que las piezas de Carteia recuperadas en Baelo Claudia sólo se encontraban en niveles imperiales, lo que por otra parte no era del todo exacto, como más tarde analizaremos.

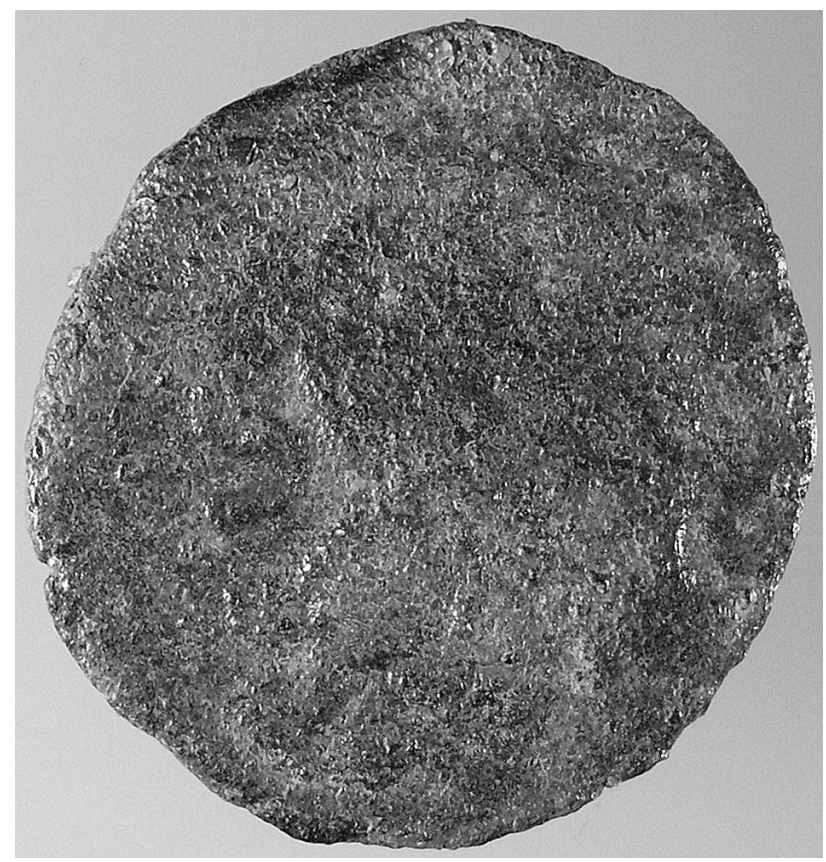

En efecto, el interés del hallazgo reside en que procede de un estrato cuyo contexto cerámico debemos situar en el último tercio del siglo II a. C., lo que no parece concordar con la cronología propuesta para esta emisión, pues Chaves la sitúa hacia el 80 a. C. Ciertamente el contexto permite datar esta emisión al menos en el último tercio del siglo II a. C., aunque si tenemos en cuenta que se trata de un ejemplar con un elevado nivel de desgaste se podría pensar en una cronología ligeramente anterior a esta fecha. De hecho, Chaves (2005:100) ha apuntado recientemente que se podria subir la cronología propuesta para las emisiones de esta ceca con

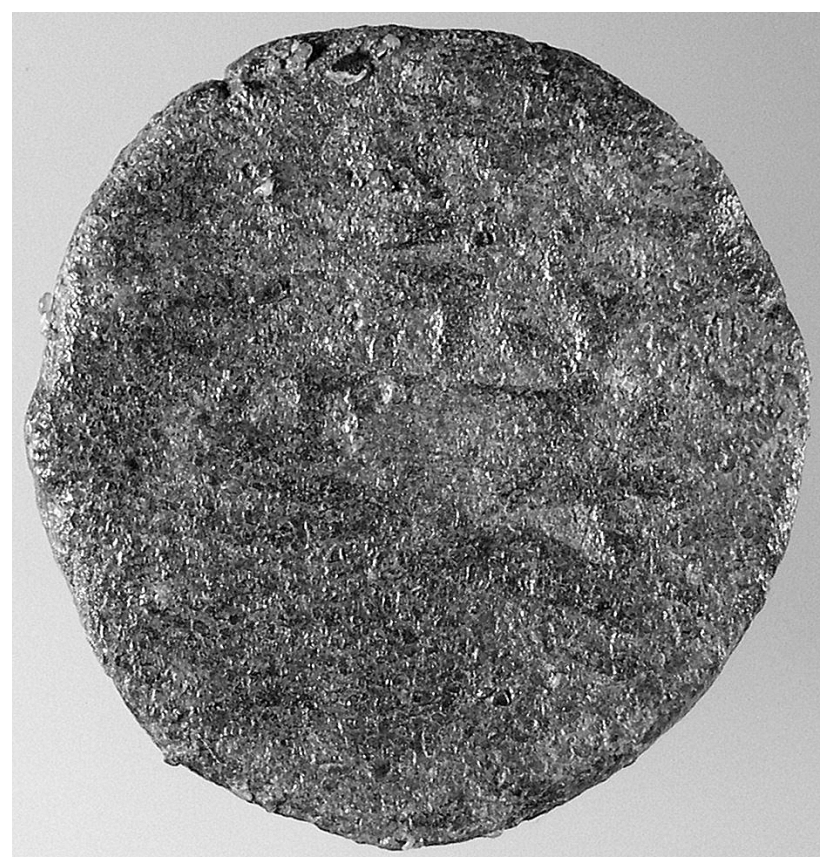

A Figura 11. Semis de Carteia recuperado en el Conjunto Industrial VI de Baelo Claudia. 
reverso proa, hasta ahora fechadas hipotéticamente a partir del 110 a. C., quizá a la década 30-20 del siglo II a. C., en base al hallazgo, que uno de nosotros publicamos (Arévalo 2005: 471-479), procedente de la Avda. Pery Junquera (San Fernando, Cádiz). Lo que sin duda el contexto de Baelo Claudia ha aportado es una referencia cronológica clara que permite replantear parte de la cronología y de la seriación de Carteia.

El otro semis de Carteia, perteneciente a la emisión 29 (RPC 122; Chaves, 1979: período IV, emisión 29), se localizó durante las excavaciones efectuadas en el actualmente denominado Edificio Meridional III, antiguo Conjunto Industrial III (fig. 12) -Sondeo II- (Bernal et al. 2007: 292-293). La interpretación de este hallazgo es compleja al proceder de un contexto datado en la segunda mitad del siglo II a. C., pues no parece concordar con la cronología defendida para esta emisión carteiense, ya que se sitúa entre finales del siglo I a. C. y principios del I d. C. Sin embargo, el hecho de que proceda de un nivel en contacto con los estratos altoimperiales fechados en el II d. C., puede ser interpretado como una intrusión de dicha época correspondiente a la alteración de los niveles republicanos, por lo que se trataría de un ejemplo de perduración en circulación de esta emisión, como se constata en otros hallazgos de la propia Baelo Claudia.

Es cierto, como por otra parte ha señalado Chaves, que los hallazgos de la emisión 29 de Carteia son frecuentes en diferentes yacimientos hispanos en niveles imperiales; remitimos al lector a los diversos estudios realizados por Chaves (1979; 1982, 287-309; 2005, 95-113) para profundizar en esta cuestión. De hecho, en Baelo sólo han aparecido monedas de esta emisión en niveles imperiales, como analizamos en el ya citado estudio monográfico, mientras que en los es- tratos republicanos no se han hallado ejemplares de esta serie, aunque si están presentes otras piezas de esta ceca, por lo que parece que esta emisión es más habitual en niveles imperiales que en los republicanos. De ahí que, convenga tener cierta cautela a la hora de considerar la moneda encontrada en el Edificio Meridional III, en un contexto datado en la segunda mitad del II a. C., como propia de este ambiente cronológico, tendremos que esperar a que nuevos hallazgos permitan clarificar esta cuestión.

Lo que no cabe duda es que estos hallazgos se suman a la frecuente presencia de moneda de Carteia en Baelo Claudia, tanto en niveles republicanos como imperiales, pues de los 91 ejemplares hispánicos de época republicana encontrados (Bost et al. 1987: nn. 1-91), el mayor número corresponde a esta ceca, con 72 piezas. Es evidente, como ya han comentado algunos autores, que no fue Bailo la que alimentó de moneda esta ciudad durante el período en que estuvo en funcionamiento la ceca, sino que lo hizo Carteia. Este hecho unido al abundante material itálico constatado en las últimas intervenciones realizadas por la Universidad de Cá$\mathrm{diz}$, ha permitido realizar una primera inferencia histórica de gran calado (Arévalo y Bernal 2007: 79-91). El aprovechamiento pesquero-conservero detectado en la ensenada de Bolonia bien pudiera haber sido realizado por la propia ciudad indigena, bien por entes cívicos más potentes o por agentes o sociedades privadas dedicados a tales fines. En este sentido, la parquedad de los datos arqueológicos sobre esta fase y la dificultad de apreciar este tipo de aspectos a través de la cultura material nos hacen ser cautos sobre el particular. Si bien pensamos que la intensa ocupación del área costera podría ser puesta en relación con los intereses de los co-
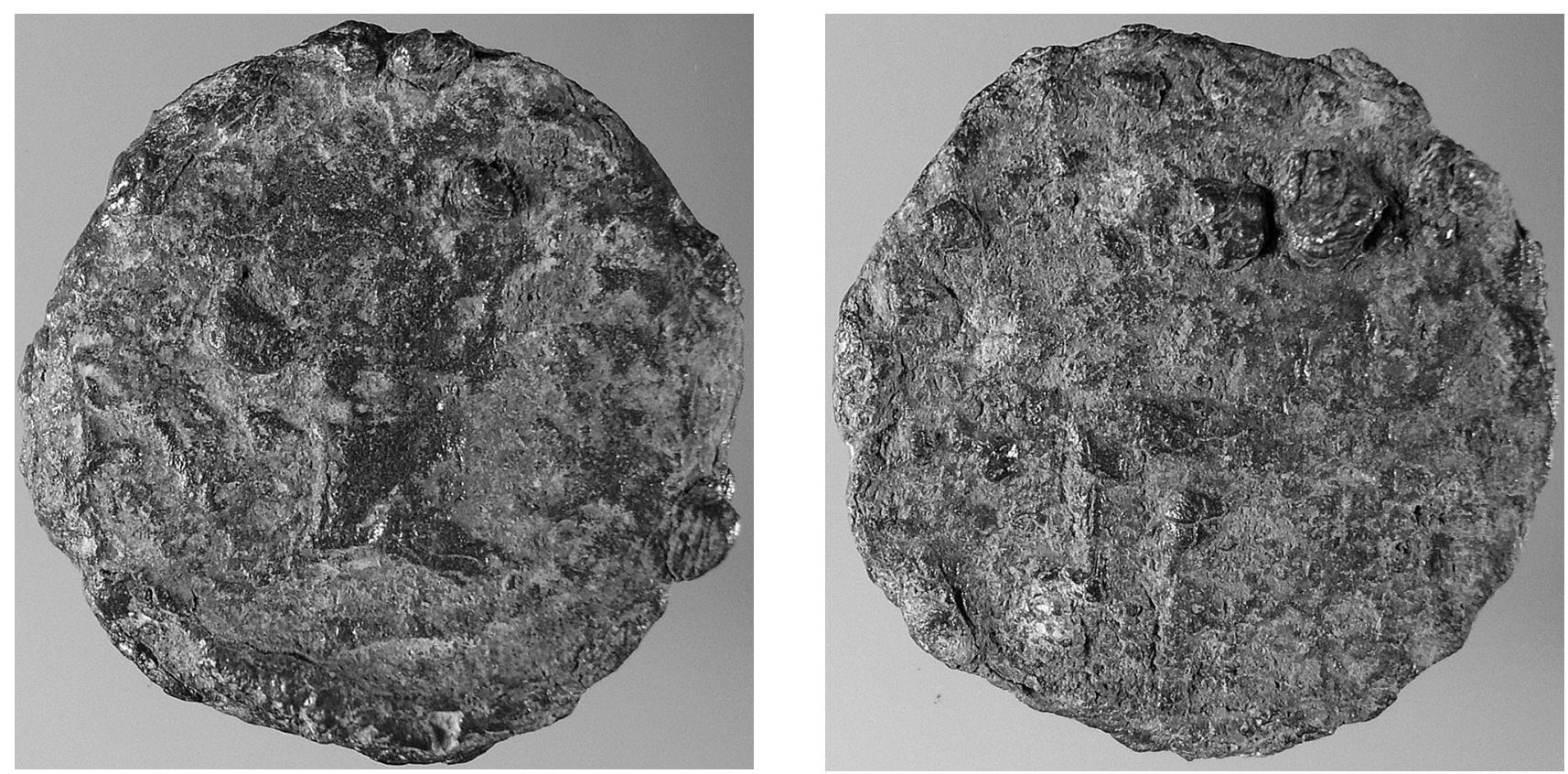

A FiguRa 12. Semis de Carteia recuperado en el Edificio Meridional III de Baelo Claudia. 
Ionos itálicos asentados en la zona del Estrecho tras la conocida deductio de Carteia en el 171 a. C. La colonización de que fue objeto esta zona durante los siglos II y I a. C., al amparo de la ciudad de Carteia, principal potencia económica del Estrecho de Gibraltar en estos momentos, explicaría la presencia mayoritaria de moneda de Carteia frente a otras cecas hispánicas.

Esta nueva información podría dar sentido a un antiguo hallazgo monetal efectuado por la Casa de Velázquez durante sus primeras intervenciones arqueológicas en esta ciudad hispanorramana, hallazgo que tratamos a continuación y que muestra el uso ritual y religioso de la moneda.

\subsubsection{Ofrenda fundacional en la factoría de salazones de Baelo Claudia}

La primera campaña emprendida por la Casa de Velázquez en 1966 en esta ciudad hispanorromana tenía por finalidad conseguir una estratigrafía lo más completa posible, a través de la cual establecer las distintas fases de ocupación del lugar (Domergue 1973: 7), para lo cual se llevaron a cabo distintos sondeos en diferente zonas de la ciudad (fig. 13). En el sondeo 26 realizado en el área meridional de la ciudad, junto al decumanus maximus, se pudo documentar los inicios de la ocupación del yacimiento de Baelo, y el hallazgo de tres monedas depositadas a modo de ofrenda fundacional.

En efecto, en el estrato VII (situado a -2,70/-3 m de profundidad) se localizó una conducción hidráulica subterránea realizada con tubuli cerámicos machihembrados y bloques pétreos bajo los que se depositaron (fig. 14), según sus excavadores, dos bronces de Bailo (figs. 15 y 16 ) y otro de ceca indígena, que Domergue (1973: 66-68, n. ${ }^{\circ} 38$ ) consideró que podría tratarse de Gadir, mientras que en el posterior estudio de las monedas de esta ciudad se atribuyó a Carteia, aunque con dudas por el mal estado de conservación de la pieza (Bost et al. 1987: n. ${ }^{\circ} 86$ ). Estas monedas fueron interpretadas como correspondientes a una deposición intencionada asociada a rituales de fundación. La cerámica asociada a este nivel era realmente escasa, con algunos fragmentos de barniz negro de tipo Campaniense $A$ y una pátera $L 7$ en Campaniense $B$ con un grafito post-cocción (¿ACAMV(...)?).

Aunque este nivel se fechó por los materiales a finales del siglo II o primera mitad del siglo I a. C. (Domergue 1973: 68), el reestudio de los contextos republicanos de Baelo Claudia llevado a cabo con motivo de los recientes resultados de las excavaciones realizadas por la Universidad de Cádiz en el área de los conjuntos industriales salazoneros III y $\mathrm{VI}$, así como en el saladero-pesquería documentado en Punta $\mathrm{Ca}$ marinal, ha permitido retrasar los orígenes de la industria pesquero-conservera en este enclave del denominado "Círculo del Estrecho", constatando los primeros momentos de uso de la zona hacia 140-130 a. C. (Arévalo y Bernal 2007: 79-91; Bernal et al. 2007: 237-354).
Estamos por tanto ante los inicios de la actividad pesquera y conservera del solar baelonense $y$, al igual que sucediera en el alfar de Torre Alta (San Fernando, Cádiz), para asegurar esta actividad y la prosperidad de la misma es probable que se realizara esta ofrenda. Para ello se escogen sendas monedas de las dos primeras series de la propia Bailo y un semis de Carteia, imposible de catalogar por su alto grado de desgaste y que denota al igual que las de Bailo un uso prolongado; es decir se eligen monedas de la propia ciudad, algo lógico por otra parte, y de la cercana Carteia, que parece que fue la encargada de alimentar monetalmente a la ciudad de Baelo, a tenor del escaso numerario propio encontrado en el yacimiento y del elevado número de ejemplares carteienses recuperados, como antes hemos comentado. Quizás ésta fue la razón de tal elección, pero debemos recordar que el aprovechamiento pesquero-conservero detectado en la ensenada de Bolonia podría ser puesto en relación con los intereses de los colonos itálicos asentados en la zona del Estrecho tras la conocida deductio de Carteia en el 171 a. C., según las últimas investigaciones realizadas, también comentadas con anterioridad (Arévalo y Bernal 2007: 79-91). La colonización de que fue objeto esta zona durante los siglos II y I a. C., al amparo de la ciudad de Carteia, principal potencia económica del Estrecho de Gibraltar en estos momentos, explicaría la presencia mayoritaria de sus monedas, al tiempo que quizás sea ésta, y no otra, la razón por la que se escoge este numerario para la ofrenda junto al de la propia Bailo.

\subsection{La Bahía de Algeciras: las monedas de las cetariae de Iulia Traducta}

En esta zona occidental del Conventus Gaditanus sobresalen las novedades de las intervenciones arqueológicas preventivas realizadas en el término municipal de Algeciras en las dos últimas décadas, que han permitido realizar una nueva propuesta interpretativa sobre la topografía y el urbanismo de la ciudad romana de Iulia Traducta (Algeciras), teniendo constancia de un poblamiento continuo entre los siglos I y VII d. C., aunque la información sobre los siglos II y III sea especialmente parca (Jiménez-Camino y Bernal 2007: 157-200).

Además, destaca el análisis de las cetariae urbanas excavadas en $\mathrm{C} /$ San Nicolás. Donde se han documentado al menos siete factorías: cuatro (Conjuntos $A, B, C$ y D) en el número 1 de la calle, así como una arteria viaria entre los Conjuntos $A$ y $B$; dos (Conjuntos I y II), en el número 3-5, además en la zona situada al norte de ambas factorías se ha detectado la existencia de una serie de pavimentaciones de diversa naturaleza y una zona porticada más cercana al Conjunto Industrial I. Por último, en el número 7 de esta misma calle se ha localizado, al menos, una factoría en el perfil sur. Estas cetariae presentan un funcionamiento ininterrumpido de casi seis 


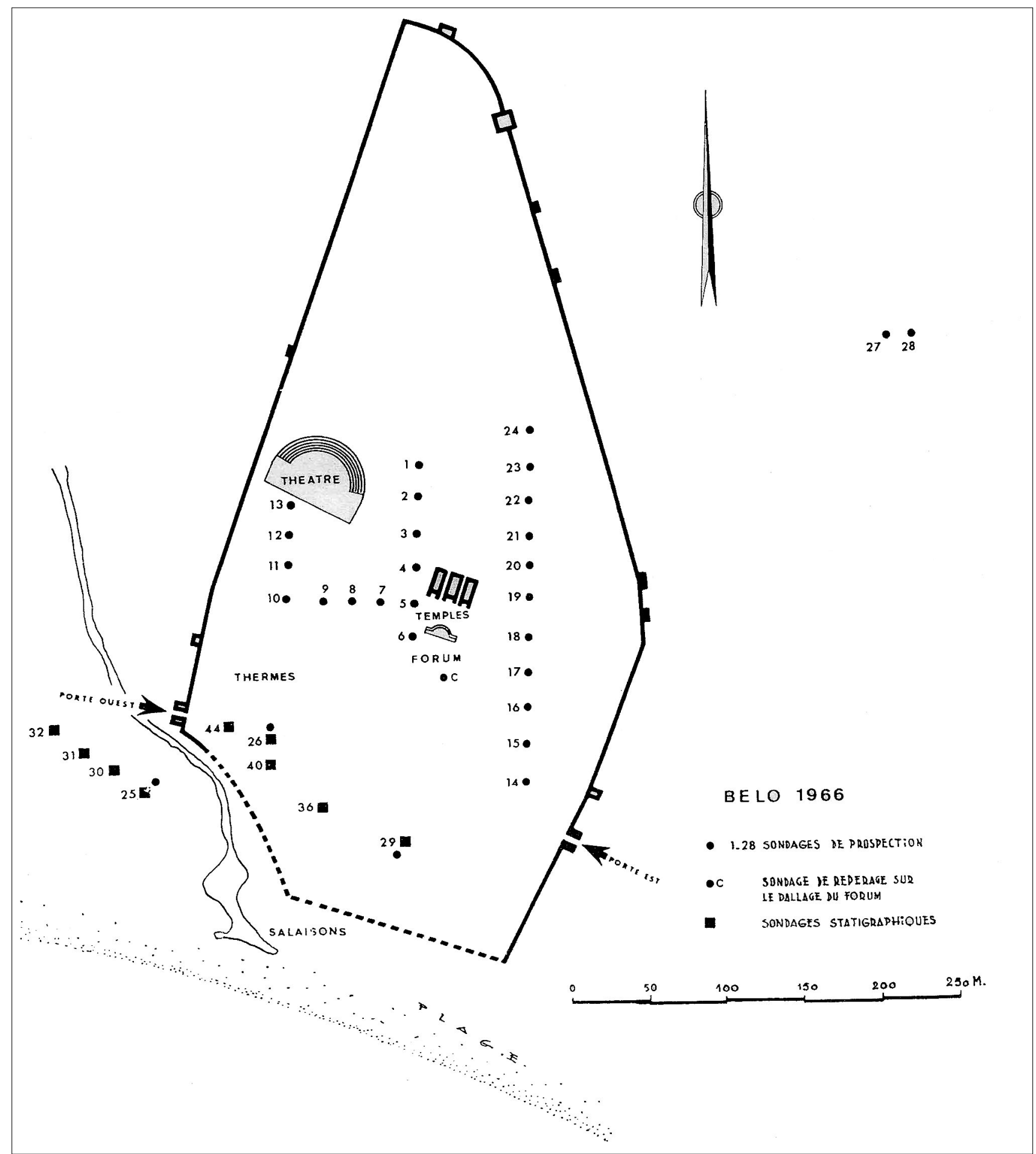

A Figura 13. Localización de los sondeos arqueológicos realizados por la Casa de Velázquez en 1966 (tomado de Domergue 1973).

siglos, aunque ha sido especialmente la época tardorromana (fig. 17), la que ha permitido contar con nuevas secuencias estratigráficas y con datos de gran cantidad de materiales, ya que la mayor parte de ellos corresponde al momento de abandono de las estructuras arqueológicas, al haber intervenido mayoritariamente a techo de muro (Bernal et al. 2003: 163184; Bernal y Expósito 2006: 293-308; Bernal 2009).
Entre estos materiales destaca el elevado número de monedas de bronce recuperadas -1174 ejemplares-, recientemente estudiadas (Arévalo y Mora 2009). La mayor parte de ellas con un contexto bien definido que cuenta con un rico y variado registro arqueológico, al tiempo que se han localizado asociadas a las distintas unidades de producción de salsas de pescado excavadas. Esto le hace ser por el mo- 


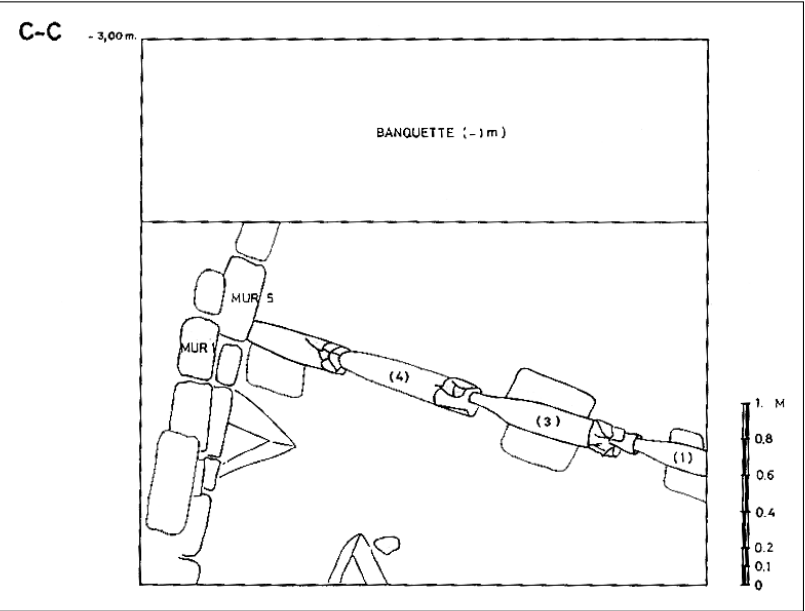

$\Delta$ Figura 14. Planta del estrato VII del sondeo 26 realizado en el área meridional de Baelo Claudia (tomado de Domergue 1973, fig. 25).

mento un caso único en el ámbito del Estrecho de Gibraltar, lo que está facilitando ampliar nuestro conocimiento sobre la circulación monetaria en esta parte de la costa del mediodía peninsular fundamentalmente durante la Antigüedad Tardía, ya que prácticamente la totalidad de las monedas recuperadas durante las excavaciones se relaciona con niveles de abandono de las diversas factorias de salazón documentadas.

Como hemos comentado este conjunto monetario procede de tres solares de la C/ San Nicolás: en el número 1 se recuperaron 104 monedas, en los números 3-5 se han recogido 1064 ejemplares (fig. 18), y los trabajos realizados en el número 7 proporcionaron seis piezas.

De las 1174 monedas, el grueso corresponden a las emisiones del siglo IV con 548 piezas, como prolongación de este importante conjunto deben considerarse las cinco monedas de la primera mitad del siglo $\mathrm{V} d$. C., las seis bizantinas, y las 47 inciertas con bastante probabilidad atribuibles a los siglos IV y V d. C. En cuanto a las monedas anteriores al siglo IV, existe una testimonial presencia de moneda hispana con sólo doce ejemplares; cantidad similar presentan los ejemplares altoimperiales con trece piezas. Mayor número encontramos en el siglo III con cuarenta y cinco monedas, a estas monedas antiguas debemos sumar las 482 piezas frustras. Por último, únicamente dieciséis pertenecen a los períodos medieval y moderno.

Es oportuno recalcar para entender el registro monetal documentado que éste es resultado del tipo de intervencio-
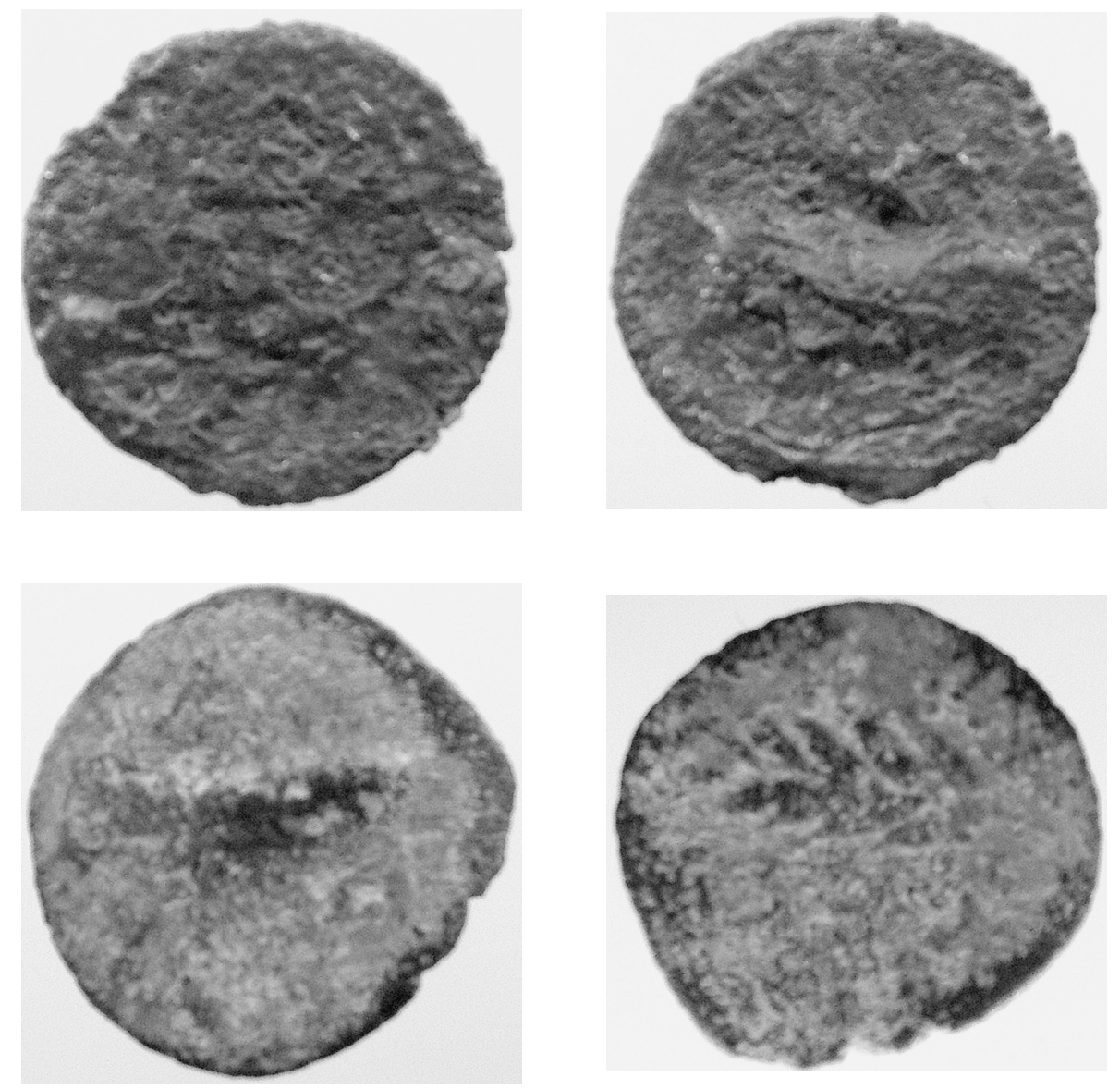

- Figuras 15 y 16. Monedas de bronce de Bailo encontradas en el estrato VII del sondeo 26 de Baelo Claudia (Museo de Cádiz). 


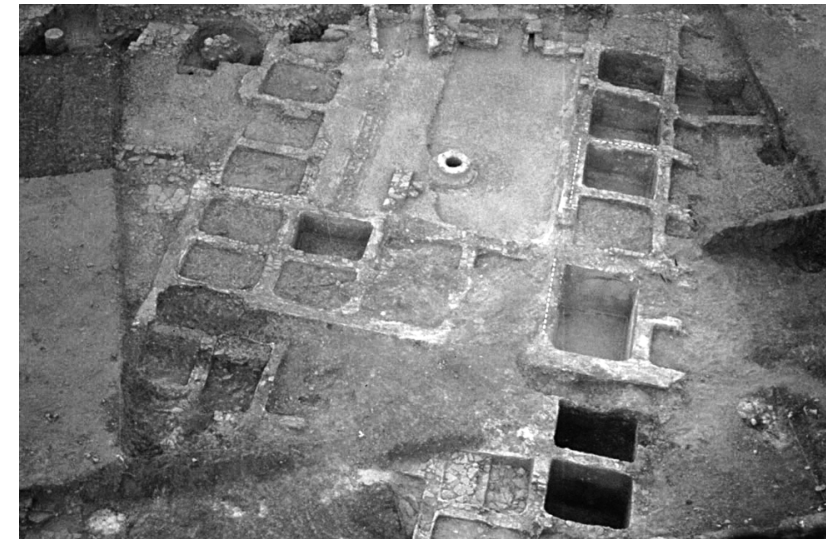

- Figura 17. Vista cenital de las factorias de salazón tardorromanas de San Nicolás (Algeciras) (cortesía de D. Bernal).

nes arqueológicas acometidas, dirigidas a conocer en extensión las factorías de salazones allí localizadas. De ahí que la información proceda fundamentalmente de niveles de abandono y cambios de ocupación de estos solares, por otra parte en casi su totalidad excavados a techo de muro, salvo en los casos puntuales en los que se han acometido sondeos estratigráficos que han permitido documentar los niveles de construcción de la factoría o en aquellas piletas vaciadas íntegramente. Deberán ser las futuras excavaciones las que permitan tener un suficiente registro monetario de los diferentes sectores y distintas fases de vida del sector industrial de Traducta.

No cabe duda que estas monedas se han convertido en un valioso documento histórico-arqueológico para conocer la Antigüedad Tardía en Traducta, y por extensión aporta nuevos datos para la reconstrucción de la historia monetaria del Estrecho. Pero además cuenta con un singular hallazgo, que será el que expondremos a continuación, y que pone de manifiesto, como en los ejemplos anteriores, el uso de la moneda en una ofrenda fundacional realizada en un ambiente industrial.

\subsubsection{Depósito fundacional en las cetariae de Iulia Traducta}

Como acabamos de comentar, en la zona situada al norte de del Conjunto Industrial I (C/ San Nicolás, 3-5) se ha detectado la existencia de pavimentos realizados bien con material pétreo, latericio, o simplemente a base de tierra apisonada. Así como un doble pórtico, cuya parte trasera estaría sustentada por pilares y cuya parte anterior lo estaría por columnas pétreas. De esta área proceden el mayor número de monedas recogidas, un total de 692, aunque son frecuentes los ejemplares ilegibles y los recortes. De todo este abundante numerario conviene destacar dos tipos de hallazgos que han sido de sumo interés tanto para la interpretación

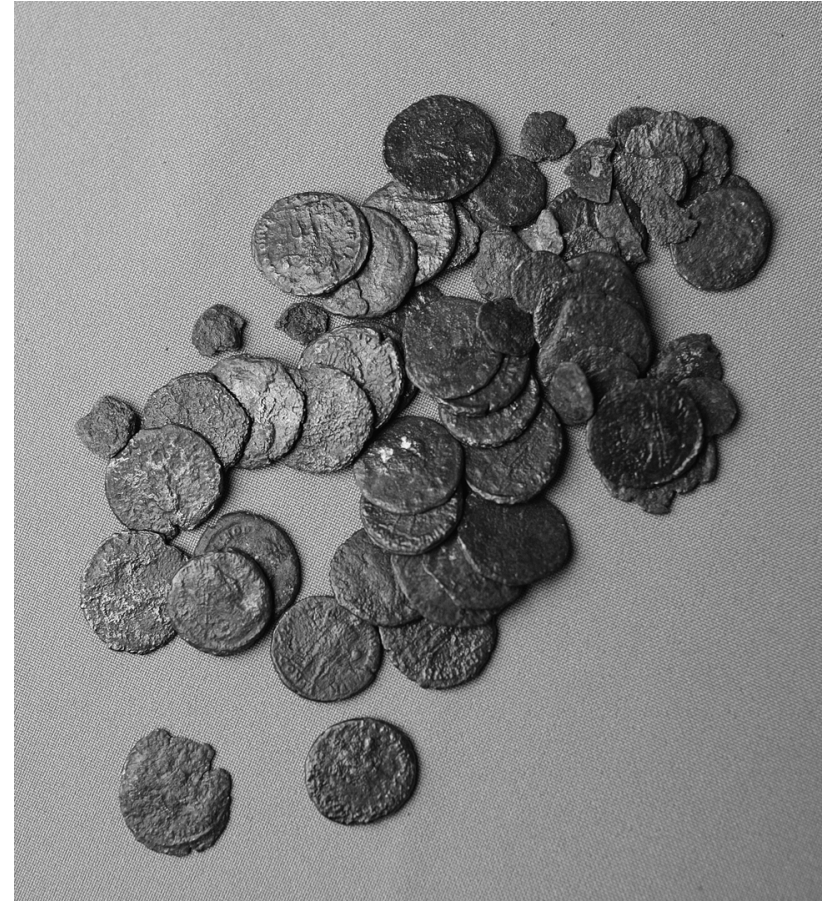

A Figura 18. Conjunto de monedas encontradas en San Nicolás 3-5 (Algeciras).

histórico-arqueológica y funcional de estos espacios; remitimos al lector al reciente estudio para conocer esta aportación (Arévalo y Mora 2009), como para conocer uno de los primeros actos que se realiza en este ambiente con motivo de la construcción de este doble pórtico, hallazgo que trataremos a continuación de forma detallada al ser un ejemplo más de este tipo de actos rituales efectuados en ambientes industriales de la costa gaditana.

En efecto, este hallazgo monetal está relacionado con los primeros momentos constructivos del citado doble pórtico y, por lo tanto, es uno de los escasos datos arqueológicos y cronológicos con que se cuenta sobre el origen de estas instalaciones, ya que, como hemos venido comentando a lo largo de estas páginas, la mayor parte de la información recuperada durante las diversas intervenciones arqueológicas se relaciona con niveles de abandono tanto de las piletas de salazón como de las restantes estructuras del complejo. Sin embargo, durante la primera campaña de excavación se llevó a cabo un sondeo estratigráfico (Sondeo II) en esta zona norte del Conjunto Industrial I, donde se había localizado parte de las estructuras arquitectónicas vinculadas al doble pórtico. Según el informe elaborado por sus excavadores (Jiménez-Camino y Tomassetti 2000: 12-13) en este sondeo se localizó "una columna de mampuestos recortados con segmentos de círculo unidos con argamasa que apoya en un cimiento cuadrangular de mampostería sin ligante sobre el cual descansa directamente el fuste... La limpieza de este cimiento proporcionó una moneda de Carteia, que, hasta su concreta adscripción a alguna de sus emisiones, nos fecha 


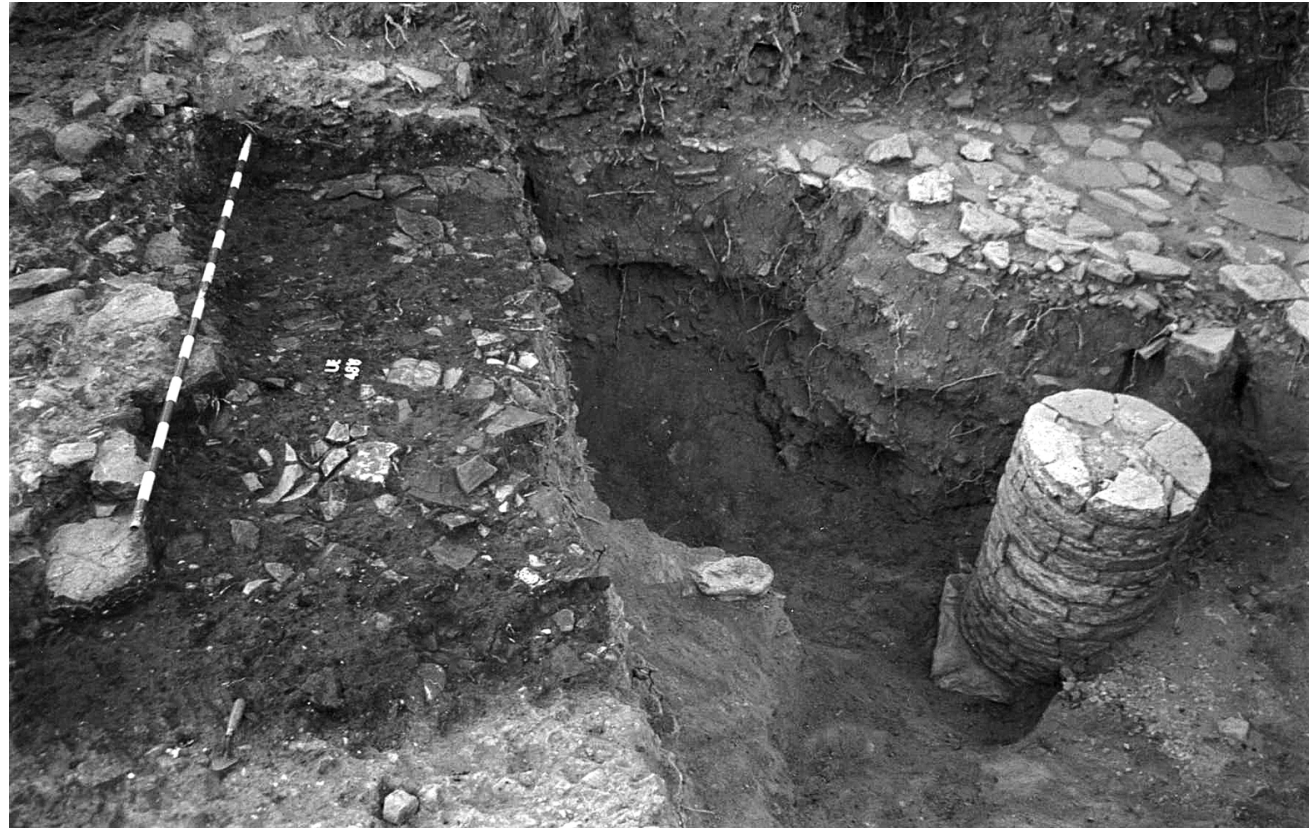

ム FiguRA 19. Columna del doble pórtico de San Nicolás 3-5 (Algeciras) en cuya cimentación se halló una moneda de Carteia (cortesía de D. Bernal).

su fundación grosso modo en un momento no posterior a mediados del s. I d. C." (fig. 19).

La moneda es un cuadrante de Carteia del cuarto periodo (Chaves 1979: 27a emisión; RPC 119) que presenta en anverso un delfín y tridente con la leyenda CARTEIA, mientras que el reverso muestra un timón y la leyenda III VIR D.D (fig. 20), y que según las últimas fechas propuestas por Chaves se dataría hacia el 20 a. C. Su hallazgo es de sumo interés por varias razones, aunque por desgracia el hecho de que se tratara de un sondeo impidió excavar en su totalidad la cimentación de esta columna, por lo que no tenemos seguridad de que no haya alguna otra moneda. Por lo que las cuestiones que vamos a plantear tienen que ser consideradas con cautela: en primer lugar, el contexto arqueológico parece claro y permite interpretarlo como un depósito fundacional. El acto de colocar objetos de cierto valor en cimientos de especial relevancia, como una forma de sacralizar el lugar, es de sobra conocido en el mundo antiguo, y son cada vez más
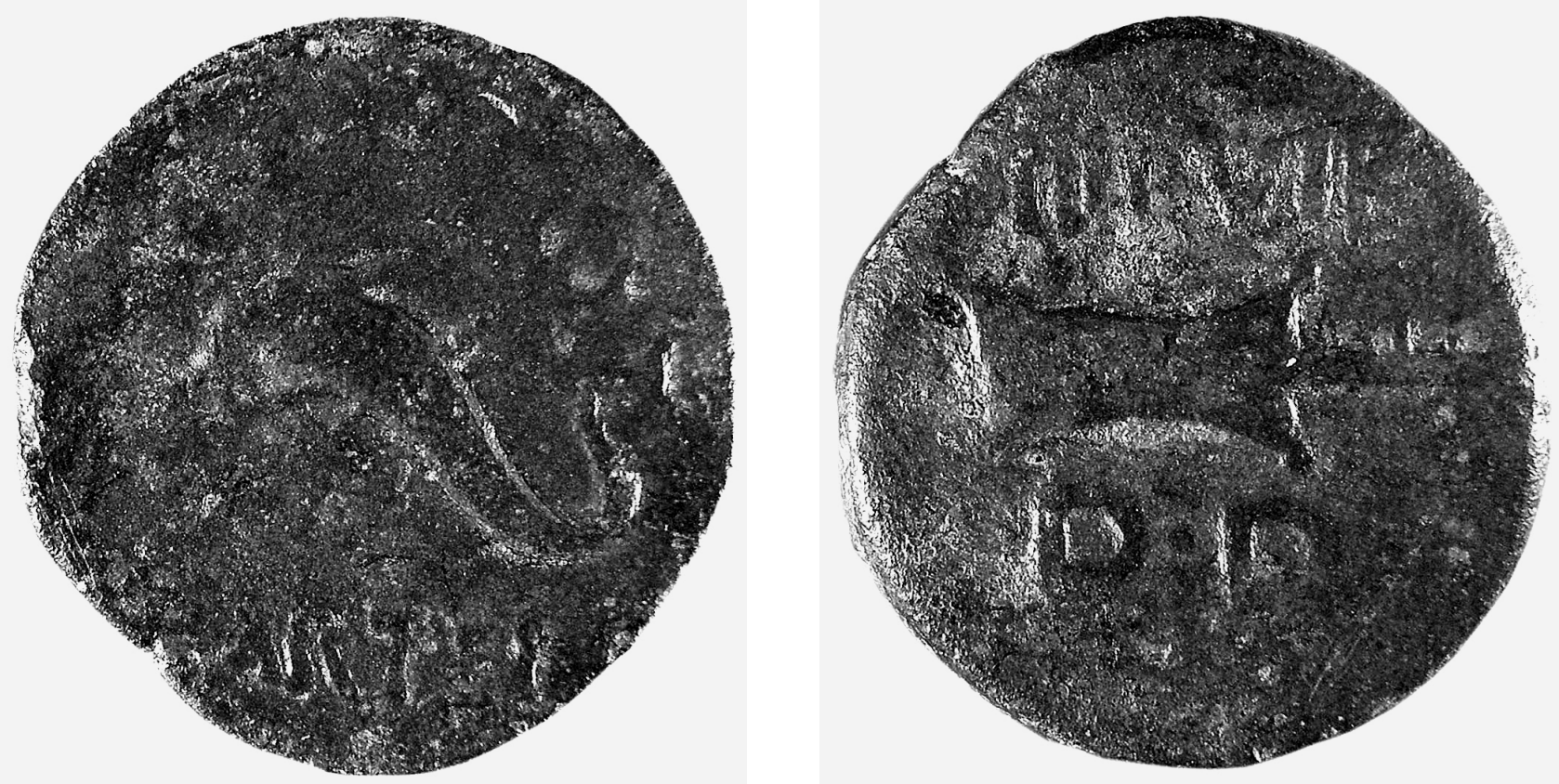

A Figura 20. Semis de Carteia encontrado en la cimentación de una de las columnas del doble pórtico de San Nicolás 3-5 (Algeciras). 
los ejemplos conocidos en la Península Ibérica, como hemos expuesto en el inicio de este trabajo. En este caso, de nuevo, parece evidente que estamos ante un acto ritual realizado en los inicios de una actividad vinculada con la industria pesquero-conservera, sin duda para asegurar la continuidad y la prosperidad de la misma. Además, la tipología de esta moneda hace una clara alusión a la actividad marinera.

En segundo lugar, es importante destacar que este hallazgo monetario permite fechar la construcción de este doble pórtico en un momento posterior a la fecha de la emisión de Carteia, obteniendo con ello una cronología relativa post quem para la misma, probablemente en época augustea, como parece indicar el escaso desgaste de la moneda. Por último, cabría preguntarse en el caso de que se confirmara que es la única moneda del depósito, el porqué se eligió esta moneda en unas instalaciones industriales vinculadas a la ciudad de Traducta. Es sabido que esta colonia fue fundada por Augusto entre 33-25 a.C., probablemente antes del 27 a. C., por el epíteto de lulia, y que emitió moneda posiblemente entre el 12-2 a.C. (Chaves 1979b: 73-74). Se podria pensar que la construcción se llevó cabo en un momento anterior a la primera acuñación de la ciudad de Traducta, escogiéndose por tanto la moneda que hasta ese momento era la de mayor prestigio en la zona, que sin duda era la emitida por la cercana Carteia. Ambas referencias cronológicas monetales nos podrian permitir aproximarnos aún más al momento de construcción, pues además de la fecha post quem que nos proporciona la moneda carteiense, contamos con una datación ante quem facilitada por la amonedación de Traducta.

Independientemente de las razones apuntadas sobre la elección del ejemplar de Carteia para forma parte de este depósito, y sobre los aspectos cronológicos que dicho hallazgo puede aportar para datar el momento de construcción del citado pórtico. Lo que no cabe duda es la interpretación del mismo, pues parece claro que se trata de la ejecución de una ofrenda fundacional en los inicios del funcionamiento de estas cetariae.

\section{MONEDAS, CETARIAE Y FIGLINAE. ALGUNAS REFLEXIONES}

Como se ha visto en los apartados precedentes existe un rico y variado volumen de monedas procedentes de los ambientes industriales pesquero-conserveros de la costa gaditana, a los que hasta ahora no se les había prestado atención, situación que podemos extrapolar al resto de nuestras costas.

Sin duda, ello es debido a la desigual e incompleta información que se tiene de estos hallazgos, cuestión que afecta no sólo a la moneda sino también a cada uno de los variados aspectos que pueden ser tratados al analizar el funcionamiento de estas estructuras industriales vinculadas con la explotación de los recursos del mar.

Tampoco debemos olvidar la falta de conocimiento sobre el papel de la moneda en estos contextos, para lo que es necesario contar con detallados testimonios sobre el lugar exacto donde aparecen y los materiales con los que aparecen asociados. Es cierto que en numerosas ocasiones se deben a pérdidas accidentales, de los que pocos datos se puede extraer para conocer el uso de la moneda en estos ambientes industriales. Aunque nos proporciona una valiosa información sobre el tipo de aprovisionamiento o la clase de numerario que circulaba, qué, como acabamos de analizar, no siempre responde a un esquema similar.

Así en la bahía de Cádiz hemos visto que es su propia moneda la que de forma casi exclusiva circula en estos establecimientos, numerario que encontramos igualmente en la necrópolis de Cádiz, y que parece indicar de forma nítida que tanto la antigua Gadir como la posterior Gades se alimentó monetalmente con su propia moneda, y no sólo durante el tiempo en que estuvo en funcionamiento la ceca, sino también en períodos posteriores, a tenor de los hallazgos en contextos de los siglos I y II d. C., y del frecuente desgaste que este numerario presenta. Por el contrario, en la antigua Baelo Claudia la moneda hispánica predominante es la de Carteia, a pesar de contar con moneda propia, si bien es verdad que se acuñó en menor cantidad y durante poco tiempo, pero esta alta presencia de numerario carteiense, como acabamos de analizar, parece que se debe más a razones de tipo histórico, vinculado con la llegada de itálicos a raíz de la fundación de lo que fuera su primera colonia en la Península, y en relación con la explotación los recursos piscícolas en esta zona de la costa gaditana. Menos conocida es la historia monetal de Iulia Traducta, pues son numerosos los ejemplares tardorromanos encontrados, pero escasos los correspondientes a los primeros momentos de existencia de esta colonia, si bien parece que junto con su propia moneda circuló la de la cercana Carteia, aunque son escasos los datos que permiten clarificar el tipo de circulación predominante, a diferencia de en Baelo Claudia o en Gades.

Sí poco conocido es el tipo de numerario circulante en estos establecimientos pesquero-conserveros, menos aún es el uso de la moneda y su vinculación con actos rituales. De ahí que la recuperación en los últimos años y la revisión de antiguos hallazgos de testimonios en los que se constata el acto simbólico de depositar una moneda nos haga reflexionar sobre el significado que para estas poblaciones pesqueras tenía la amonedación. Así, parece claro que además de su valor monetal, veian en ellas un valor religioso, quizás por la iconografía que presentaban o por el hecho de constituir un pago o intercambio para gozar de los favores deseados o solicitados a ciertas divinidades. No podemos dejar de destacar que estos momentos muchas ciudades del entorno utilizan como emblemas ciudadanos motivos marinos y entre ellos 
los peces, simbolizando la marinera vocación de las mismas y la importancia de la economía pesquera en su vida cotidiana.

Sin duda, los obligados viajes migratorios de los atunes en las rutas de desove entre el Atlántico y el Mediterráneo, unidos al carácter marinero de las poblaciones ribereñas de sus costas, han provocado que esta zona sea privilegiada para las actividades de tipo haliéutico. Hundiendo sus raices en los orígenes de la civilización, al menos desde época fenicia, allá por las postrimerías del s. VIII a. C. al menos, los atunes y los peces pelágicos fueron explotados de forma intensiva, generando una fecunda industria que a partir de época romana alcanzó niveles elevadísimos de productividad, inundando todos los mercados del Imperio y dando fama a esta zona de la Hispania meridional por la calidad de sus salazo- nes, la destreza de sus pescadores y la fecundidad de sus pesquerías.

Parece que fueron estas las razones que llevaron a realizar ofrendas, depósitos y actos rituales cuya finalidad sería la de solicitar un funcionamiento óptimo de esta industria, vinculada con su fundamental actividad económica, la pesquero-conservera. $Y$ en esta práctica incorporan la moneda, tal vez con la idea de establecer con la divinidad la misma relación que se crea con el comercio; es decir, si para obtener un objeto debe pagarse, para lograr un favor se adopta idéntico criterio. Pero además al ser las monedas portadoras de una iconografía en muchos casos sacra, pudo ser utilizada por su valor religioso, pasando a incorporarse dentro de las ofrendas votivas realizadas en estos ambientes industriales.

\section{BIBLIOGRAFÍA}

AbAd Varela, M., 1992: La moneda como ofrenda en los manantiales. Espacio, Tiempo y Forma. Serie II, 133-192.

- 2006: Ofrendas en manantiales termales de la Península. En Moneda, cultes i ritus. Barcelona, 131-149.

Alfaro Asins, C., 1988: Las monedas de Gadir/Gades. Madrid.

- 1993: El uso no monetal de algunas monedas púnicas de la Península Ibérica. Moneta e non moneta. Revista Italiana di Numismatica e Scienze Affini, XVC, 27-61.

Arévalo GonzÁlez, A., 1994: La dispersión de las monedas de Ilipa Magna. En XI Congreso Nacional de Numismática. Elche, 39-48.

- 1996: La circulación monetaria en las minas de Sierra Morena: el distrito de Córdoba. Numisma, 237, 51-82.

- 1999: La ciudad de Obulco: sus emisiones monetales. Sigüenza (Guadalajara).

—, 2000: La moneda hispánica en relación con la explotación minera y agrícola. En Moneda i administraciò del territori. Barcelona, 37-56.

- 2002-2003: Las imágenes monetales hispánicas como emblemas de Estado. Cuadernos de Prehistoria y Arqueología de la UAM, 2829, 241-258.

- 2004: Sobre la presencia de moneda en los talleres alfareros de San Fernando (Cádiz). En D. Bernal y L. Lagóstena (eds.): Actas del Congreso Internacional Figlinae Baeticae. Talleres alfareros y producciones cerámicas en la Bética romana (ss. I/ a.C.-VII d.C.). Oxford, BAR Internacional Series 1266, 515-526.

- 2005: Aportación a la circulación monetaria de la Bahía de Cádiz: los hallazgos monetarios de la Avda. Pery Junquera (San Fernando, Cádiz). En XIII Congreso Internacional de Numismática. Madrid, 471-479.

—, 2006a: La moneda antigua del Museo de Cádiz. Valoración de un reciente proyecto de investigación. En D. BERNAL, B. RAISSOUNI, RAmos i A. Bouzouggar (eds.): Actas del I Seminario Hispano-Marroquí de especialización en arqueología. Cádiz, 297-308.

- 2006b: El valor simbólico y el uso cultual de la moneda en la costa gaditana, Moneda, cultes i ritus. Barcelona, 75-98.

- 2006c: Sobre el posible significado y uso de algunas contramarcas en moneda de Gadir/Gades. Numisma, 250, 69-100.

- en prensa, a: La moneda en el ámbito funerario y ritual de la necrópolis de Cádiz: Los hallazgos en pozos. En A. Arévalo (ed.): XIII Congreso Nacional de Numismática (Cádiz 2007).

- en prensa, b: Monedas para el más allá. Un primer acercamiento desde la necrópolis de Cádiz. En Homenaje a Francisco Sibón. Cádiz.
ArÉVAlo, A. y Bernal, D., 2007: Los orígenes de la industria pesqueroconservera en Baelo Claudia (ss. II-I a.C.). En L. LAgóstenA, D. BeRNAL y A. ARÉVAlo (eds.): Actas del Congreso Internacional CETARIAE. Salsas y salazones en Occidente en la Antigüedad (Cádiz, 2005), B.A.R., Oxford, 79-91.

- (eds.), 2007: Las cetariae de Baelo Claudia. Avance de las investigaciones en el barrio industrial (2000-2004), Cádiz.

ArÉVAlo, A. y Marcos, C., 2000: Sobre la presencia de moneda en los santuarios hispánicos. En XII Congreso Internacional de Numismática. Berlín, 27-38.

Arévalo, A. y Mora. B., 2009: Las monedas de las cetariae de Traducta. Un ejemplo de circulación monetaria en el Estrecho de Gibraltar en la Antigüedad Tardía. En D. BeRnAL, (ed.): Las factorías de salazón de Traducta. Primeros resultados de las excavaciones arqueológicas en la C/San Nicolás de Algeciras (2000-2006). Algeciras, en prensa.

Bernal, D. (ed), 2009: Las factorías de salazón de Traducta. Primeros resultados de las excavaciones arqueológicas en la C/San Nicolás de Algeciras (2000-2006). Algeciras, en prensa.

Bernal, D., Arévalo, A. y Sáez, A., 2007: Nuevas evidencias de la ocupación en época republicana (ss. II-I a.C.). En A. ArÉvalo y D. BernAL (eds.), Las cetariae de Baelo Claudia. Avance de las investigaciones en el barrio industrial (2000-2004), Cádiz, 237-354.

Bernal, D., Arévalo, A., Lorenzo, L. y Cánovas, A. 2007: Abandonos en algunas insulae del barrio industrial a finales del siglo II d.C. En A. Arévalo y D. Bernal (eds.): Las cetariae de Baelo Claudia. Avance de las investigaciones en el barrio industrial (2000-2004), Cádiz, 383454

Bernal, D., Arévalo, A., Expósito, J.A. y Díaz, J.J. 2007: Reocupaciones del espacio y continuidad habitacional en el Bajo Imperio (ss. III y IV d.C.). En A. Arévalo y D. Bernal (eds.), Las cetariae de Baelo Claudia. Avance de las investigaciones en el barrio industrial (20002004), Cádiz, 455-488..

BernAL, D. y ExPósito, J.A., 2006: Nuevas cetariae en lulia Traducta. Avance del control arqueológico en calle San Nicolás, 1. Almoraima, 33, 293-308.

Bernal, D., Jiménez-Camino, R., Lorenzo, L., Torremocha, A. y Expósito, J.A., 2003: Las factorías de salazones de "Iulia Traducta": espectaculares hallazgos arqueológicos en la calle San Nicolás, 3-5 de Algeciras. Almoraima, 29, 163-184.

Bernal, D. y Lagóstena, L. (eds.) 2004: Actas del Congreso Internacional Figlinae Baeticae. Talleres alfareros y producciones cerámicas en la Bética romana (ss. II a.C.-VII d.C.). Oxford, BAR Internacional Series 1266. 
Bost, J.P. et al., 1987: Belo IV. Les monnaies. Madrid.

Burnetr, A., Amandry, M. y Ripollès, P.P., 1992: Roman Provincial Coinage. Londres-Paris, vol. I (citado como RPC).

CAMPO, M., 1993: Objetos paramonetales y monedas objeto en Emporion/Emporiae. Moneta e non moneta. Revista Italiana di Numismatica e Scienze Affini, XVC,193-205.

—, 2006: Usos rituals i valor religios de la moneda a l'Illa d'Ebusus (segle III a.C.-inici I d.C.). En Moneda, cultes i ritus. Barcelona, 4774.

CURTIS, R., 1991: Garum and salsamenta in materia medica. Leiden.

ChAVEs TRISTÁN, F., 1987-88: Aspectos de la circulación monetaria de dos cuencas mineras andaluzas: Riotinto y Cástulo (Sierra Morena), Habis, 18-19, 613-637.

—. 1979a: Las monedas de Carteia. Barcelona.

- 1979b: Las cecas hispanorromanas de Ebora, Iulia Traducta y CoIonia Romula, Numisma, 156-161, 9-92.

- 1982: Monedas halladas en las campañas de excavación de 1974 y 1975. En F. PRESEDo et al., Excavaciones Arqueológicas en Espa$\tilde{n} a, 120$, Madrid, 287-309.

—, 2005: De la muerte de Sartorio al paso de Rubicón: un período oscuro para la numismática del sur hispano. En La moneda al final de la República: entre la tradició y la innovació, Barcelona, 95-114.

Chaves, F. y Garcia, E., 1991: Reflexiones en torno al área comercial de Gades. Estudio histórico y económico. Gerión. Alimenta: homenaje al Dr. M. Ponsich, Madrid, 139-168.

Chaves Tristán, F. y Otero Morán, P., 2002: Los hallazgos monetales. En J.Ma Blázquez Martínez, C. Domergue y P. Silliėres (dir.), La Loba (Fuenteobejuna, Cordue, Espagne. La mine et le village anticues. Bourdeax, 163-230.

DOMERGUE, C., 1973: Belo I. La stratigraphie. Madrid.

ETIENNE, R. y MAYET, F., 2002 : Salaisons et sauces de poissons hispaniques. Paris.

Expósıto, J.A., 2007a: ¿Dónde se encuentran las cetariae de Gades? Revisión arqueológica y estado de la cuestión sobre el emplazamiento de las factorías de salazón romanas de la ciudad de Cádiz. En L. Lagóstena, D. Bernal y A. Arévalo (eds.): Cetariae. Salsas y salazones de pescado en Occidente durante la Antigüedad (Cádiz, noviembre 2005), Oxford, BAR Internacional Series, 367-385.

—, 2007b: Las factorías de salazón de Gades (s.ll a.C.-VI d.C). Estudio arqueológico y estado de la cuestión. Cádiz. http://minerva.uca.es/ publicaciones/asp/tesis.asp:

Frutos ReYes, G. DE y Muñoz Vicente, A., 1994: Hornos púnicos de Torrealta (San Fenando, Cádiz). En Arqueología en el entorno del Bajo Guadalquivir, Huelva, 393-414.

Garcia-Bellido, Ma P. 1982: Las monedas de Castulo con escritura indigena. Historia numismática de una ciudad minera. Barcelona.

- 1986: Nuevos documentos sobre minería y agricultura romana en Hispania. Archivo Español de Arqueología, 153-154, 13-46.

- 1999: Los resellos militares en moneda como indicio de movimientos de tropas. En II Encuentro Peninsular de Numismática Antigua, Madrid, 55-70.

Garcia-Bellido, Mà P. y Blázouez, C. (2001): Diccionario de cecas y pueblos hispánicos, Madrid.

GARCIA VARGAS, E. 1998: La producción de ánforas en la bahía de Cádiz en época romana (siglos II a.C.-IV d.C.). Écija.
—, 2001: Pesca, sal y salazones en las ciudades fenicio-púnicas del sur de Iberia. En XV Jornadas de Arqueología Fenicio-Púnica. Ibiza, 966.

Garcia Vargas, E. y Ferrer Albelda, E., 2002: Las salazones de pescado de la Gadir púnica. Estructuras de producción, Laverna, 12.

JimÉnEZ-CAmino, R. y BernaL, D., 2007: Redescubriendo a Traducta. Reflexiones sobre su topografía urbana y su secuencia ocupacional (ss. I - VII). Anales de Arqueología Cordobesa, 18, 157-200.

Jiménez-Camino Álvarez, R. y Tomassettı GuerRa, J.M., 2000: Informe preliminar. Intervención Arqueológica de Urgencia en el solar sito en los n. ${ }^{\text {s }} 3$ y 5 de la calle de San Nicolás, en la Villa Vieja de Algeciras (Cádiz): Diagnóstico previo. Cádiz (Informe inédito depositado en la Delegación Provincial de Cultura de Cádiz).

LAgóstena BARRIOS, L., 1996: La alfarería romana en la bahía de Cádiz. Cádiz.

- 2001: La producción de salsas y conservas de pescado en la Hispania romana. Barcelona.

Lagóstena BarRios, L. y BeRnAl CASASOLA, D., 2004: Alfares y producciones cerámicas en la provincia de Cádiz. Balance y perspectivas. En D. Bernal y L. Lagóstena (eds.): Actas del Congreso Internacional Figlinae Baeticae, B.A.R. int. ser. Oxford, 39-124.

Lagóstena, L., Bernal, D. y Arévalo, A., (eds.): 2007: Actas del Congreso Internacional CETARIAE. Salsas y salazones en Occidente en la Antigüedad (Cádiz, 2005), BAR., Oxford.

Martinez, A. y CAstellano, J.J., 1995: Conjunto de fusayolas ibéricas de dos cuevas santuario de la comarca de Requena-Utiel. En XXIII Congreso Nacional de Arqueología, Elche, 525-536.

MuÑOz VICENTE, A., 1993: Las cerámicas fenicio-púnicas de origen submarino del área de La Caleta (Cádiz), Cuadernos de Prehistoria y Arqueología Castellonense, 15.

Muñoz Vicente, A., Frutos Reyes, G. de y Berriatúa, N., 1988: Contribución a los orígenes y difusión comercial de la industria pesquera y conservera gaditana a través de las recientes aportaciones de las factorias de salazones de la bahía de Cádiz. En Congreso Internacional del Estrecho de Gibraltar, Madrid, 487-508.

MOLINA, F.; RUIz, A. y HUERTAS, C., 1982: Almuñecar en la Antigüedad. La necrópolis fenicia de Puente Noy, Granada.

Ponsich, M., 1988: Aceite de oliva y salazones de pescado. Factores geoeconómicos de Bética y Tingitani., Madrid.

SÁez Romero, A., 2004: El alfar tardopúnico de Torre Alta. Resultados de las excavaciones de 2002-2003. En D. Bernal y L. LagóstenA (rds.): Actas del Congreso Internacional Figlinae Baeticae. Talleres alfareros y producciones cerámicas en la Bética romana (ss. II a.C.-VII d.C.). Oxford, BAR Internacional Series 1266, 699-712.

- 2008: La producción cerámica de Gadir en época tardopúnica (siglos (II-I). Oxford, BAR Internacional Series s1812, 2 vols.

SÁNCHEZ LOAIZA, V., 2008: La circulación monetaria en los centros industriales púnicos y romano de la bahía gaditana: cetariae y figlinae. Memoria DEA de la Universidad de Cádiz, inédita.

- en prensa: Las monedas de la factoria de salazón de La Algaida (Sanlúcar de Barrameda, Cádiz). En A. ARÉVAlo (ed.): Actas del XIII Congreso Nacional de Numismática (Cádiz, noviembre 2007).

SILLİERES, P., 1995: Baelo Claudia. Une cité romaine de Bétique. Madrid. VILLARONGA, L., 1994: Corpus Nummum Hispaniae ante Augusti aetatem. Madrid (citado como CNH). 